\title{
Big data reveals deep associations in physical examination indicators and can help predict overall underlying health status
}

\author{
Haixin Wang ${ }^{1 \#}$, Ping Shuai ${ }^{2 \#}$, Yanhui Deng ${ }^{1 \#}$, Jiyun Yang ${ }^{1}$, Shanshan Zhang ${ }^{1}$, Yi Yin ${ }^{1}$, Lin Wang ${ }^{2}$, \\ Dongyu $\mathrm{Li}^{2}$, Tao Yong ${ }^{3}$, Yuping Liu ${ }^{2 *}$ and Lulin Huang ${ }^{1 *}$
}

${ }^{1}$ The Key Laboratory for Human Disease Gene Study of Sichuan Province, Department of Clinical Laboratory, Sichuan Provincial People's Hospital, School of Medicine, University of Electronic Science and Technology of China, Chengdu, China;

${ }^{2}$ Health Management Center \& Physical Examination Center of Sichuan Provincial People's Hospital, School of Medicine, University of Electronic Science and Technology of China, Chengdu, China;

${ }^{3}$ Medical Information Center of Sichuan Provincial People's Hospital, School of Medicine, University of Electronic Science and Technology of China, Chengdu, China.

\# These authors contributed equally.

*Correspondence should be addressed to: Lulin Huang, Ph.D. Email: huangluling@ yeah.net or Yuping Liu, Email: liuyuping555@126.com

32 The First Ring Road West 2, Chengdu, Sichuan 610072, China,

Phone: 86-28-87393375,

Fax: 86-28-87393596. 


\begin{abstract}
Because of lacking of the systematic investigation of correlations between the physical examination indicators (PEIs), currently most of them are independently used for disease warning. This results in very limited diagnostic values of general physical examination. Here, we first systematically analyzed the correlations between 221 PEIs in healthy and in 34 unhealthy states in 803,614 peoples in China. We revealed rich relevant between PEIs in healthy physical status (7,662 significant correlations, $31.5 \%$ of all). However, in disease conditions, the PEI correlations changed. We further focused on the difference of these PEIs between healthy and 35 unhealthy physical status, 1,239 significant PEI difference were discovered suggesting as candidate disease markers. Finally, we established machine learning algorithms to predict the health status by using 15\%-16\% PEIs by feature extraction, which reached $66 \%-99 \%$ precision predictions depending on the physical state. This new encyclopedia of PEI correlation provides rich information to chronic disease diagnosis. Our developed machine learning algorithms will have fundamental impact in practice of general physical examination.
\end{abstract}


The comprehensive primary healthcare system has had a broader impact on human health compared to clinical medical treatment ${ }^{1-4}$. Health examinations help those who are healthy to improve their understanding of their own physical functions and maintain their health status, and inform those as to the health benefits conferred by changing unhealthy habits and avoiding risk factors that can lead to disease $^{5}$. Physical examinations can help minimize the distress of diseases ${ }^{6}$. With the population size grows and ages, people's healthcare needs are constantly increasing, and health-care provisions are becoming more sophisticated and in parallel, more costly ${ }^{7}$.

Health examinations are common elements of healthcare in developed countries ${ }^{8}$. These checks consist of general blood examination, urine examination, blood glucose examination, blood lipid examination, renal function examination and so on. However, currently, the physical examination report is assessed mainly based on one or two independent physical examination indicators (PEIs), which can only provide very limited information for physical examiners about their healthy condition or disease diagnosis ${ }^{9-11}$. The correlations between PEI in different physical states (i.e. healthy, hypertension, diabetes) have not been systematically investigated, even though they are expected to provide valuable information for public health care, for example by defining a small set of easily measurable PEIs that can be used in the accurate diagnosis of a disease before the disease phenogenesis.

The recent explosion of available health data promises to transform healthcare by improving care quality and as such, improving population health while constraining escalating costs ${ }^{12}$. Health examination centers generate systematic big data that has the capacity to reveal otherwise undetected underlying health issues ${ }^{13-14}$. In clinical, there is growing investment in developing big data applications for medical care, such as those based on artificial intelligence (AI) to diagnosis diseases based on clinical images ${ }^{15-17}$. Although AI can save cost and improve efficiency, especially for early diagnosis and prevention of chronic diseases ${ }^{18}$, because of insufficient systematic analysis of PEIs in physical status, currently no prediction models were generated for physical status predictions based on PEIs.

As China's 2009 health-care reform has made impressive progress in expansion of insurance coverage, now general physical examination industry accumulates big data ${ }^{19}$. By using a large dataset of general health examination of Chinese population, the present study had three main aims: to 
determine the correlations among PEIs in healthy and unhealthy (namely, those with underlying chronic disease) patients; to elucidate the relationship between chronic disorders and normal individuals for these PEIs to discovery candidate disease markers; to develop machine learning models that can predict individual health status using a refined set of PEIs. To address these points, we included physical examination data from 80,3614 individuals who visited one health examination center between 2013 and 2018 in China. We included data from 221 PEIs associated with 35 physical conditions, with the majority unhealthy physical states being due to chronic disease.

\section{Results}

\section{Study population}

The study population was mainly from the Chengdu Plain, Sichuan, P.R. China $\left(102.54^{\circ} \mathrm{E} \sim 104.53^{\circ} \mathrm{E}\right.$ and $30.05^{\circ} \mathrm{N} \sim 31.26^{\circ} \mathrm{N}$ ). We included 803,614 individuals who attended the Health Management Center \& Physical Examination Center of Sichuan Provincial People's Hospital in China between 2013 and 2018. The participants represented 35 healthy states based on either a healthy status or the presence of an underlying disease condition (unhealthy status). Specifically, the study population included 711,928 healthy participants, 46,981 patients with hypertension, 11,745 patients with diabetes and 32,960 with other unhealthy status (mainly are chronic disease) (Table 1). We included 221 PEIs in our analyses, which comprised patient demographic information (age and sex) and life-style indicators (alcohol consumption, tobacco use, etc.) (Extended data Table 1).

\section{PEI correlations in participants with a healthy physical status}

We first aimed to explore the PEI correlations in healthy status to give a landscape. Among 221 PEIs, we found 7,662 significant correlations $\left(P<0.05 / 24,322\right.$ PEI pairs $\left.=2 \times 10^{-6}\right)$ in all 24,322 PEI pairs correlations $(31.5 \%)$ (Table 1, Supplementary Table 1) in those with a healthy physical status $(N=711,928$, mean age 41.4 , female $=45.7 \%)$. This finding suggests a wide range of correlations between PEIs (Fig.1). The top 50 correlated PEIs included sex, age, red blood cell count, prealbumin (PAB), history of alcohol intake (alcohol consumption, drinking), alkaline phosphatase level (ALP), tobacco use (smoking) and so on (Fig. 1a). Among the 221 PEIs, the number of significantly correlated PEIs also suggested rich correlations between PEIs (Fig. 1b). Of these identified correlations among PEIs in healthy status, some of them are consistent with the reported literatures, but most of them are newly discovered in this study. 
General inspection PEIs showed rich relevance to each other or to other PEIs. For example, sex showed the richest PEI correlations (151 PEI pairs, males vs. females), including hemoglobin (Hb), creatinine, uric acid (UA), drinking, smoking, body mass index (BMI) and etc., which reflect the differences in body shape, physique and living habits between males and females (Fig. 1, Fig. 2, Supplementary Table 1). Age also showed strong PEI correlations (125 PEI pairs), such as estimated glomerular filtration rate (eGFB), systolic pressure (SBP), diastolic pressure (DBP), albumin (Alb), and low-density lipoprotein (LDL-C). These findings suggest that with increasing age, body functions systematically change (Fig. 1, Fig. 2, Supplementary Table 1). We also found 124 PEI correlations with BMI which reflects the strong influence of body shape on PEIs, including UA, high-density lipoprotein (HDL-C), SBP, and DBP (Fig. 1, Fig. 2, Supplementary Table 1). Blood pressure (BP), which has many physiological meanings, we identified a set of PEIs that correlated with blood pressure (BP), including 125 PEIs for DBP and 124 PEIs for SBP (Fig. 1, Fig. 2, Supplementary Table 1). Intraocular pressure (IOP) is an important factor for the diagnosis of glaucoma ${ }^{8-9}$. We found 79 PEIs that were weakly correlated with IOP of the left eye (IOP-L), including IOP of the right eye (IOP-R) SBP, DBP, Alb, BMI, TG, ApoB, drinking, and TC. Similar to IOP-L, 73 PEIs were weakly correlated with IOP-R (Fig. 1, Fig. 2, Supplementary Table 1).

As expected, blood lipid PEIs display many correlations. For example, 119 PEIs correlated with triglyceride (TG) (Fig. 1, Fig. 3, Supplementary Table 1). We found 122 PEIs that correlated with HDL-C, with many negative correlations, including TG, UA, and BMI (Fig. 1, Fig. 2, Supplementary Table 2). The correlation patterns between LDL and HDL showed a specific opposite trend (Fig. 1, Fig. 2, Supplementary Table 1). Out of expected, living habits have a profound impact on our body. Consistently we detected 130 PEIs that correlated with drinking, such as sex, smoking, Hb and UA (Fig. 1, Fig. 2, Supplementary Table 1). Similarly, 128 PEIs were correlated with smoking, including drinking, sex and age (Fig. 1, Fig. 2, Supplementary Table 1). We also detected 58 PEIs that weakly correlated with exercise habits (e-habits), including age, eGFB, and SBP (Fig. 1, Fig. 2, Supplementary Table 1). Tumor marker expression can indicate the occurrence and development of tumors. We detected weak correlations between several tumor markers and PEIs. For example, 88 PEIs were correlated with cytokeratin-19-fragment CYFRA21-1 (CYFRA 21-1); 83 PEIs were correlated with tumor-supplied group factors (TSGF); 64 PEIs were correlated with neuron-specific enolase (NSE); 
and 64 PEIs were correlated with complexed prostate special antigen (C-PSA) (Fig. 1, Fig. 2, Supplementary Table 1).

\section{PEI correlations in individuals with an unhealthy physical status}

Next, we examined the PEI correlations in 34 unhealthy physical states. In this analysis, we also identified rich correlations in these unhealthy physical states (Table 1). Compared with the healthy physical state, we found fewer significant correlations in PEIs in those with an unhealthy physical status, which might be caused by sample size effect (Table 1, Supplementary Table 2-S35). Each unhealthy physical state has its only correlation spectrum and most of them are newly discovered in this study. For example, in the hypertension population, we found 4,413 significant correlations in the 221 PEIs of 24,322 PEI pairs (18.3\%) (Supplementary Table 2). The PEI with increased correlations included monocytes (MON) (70 in hypertension vs six in healthy physical state, the same below), quantitative detection of hepatitis B virus DNA (HBV-DNA) (76 vs 33), quantitative detection of hepatitis C virus RNA (HCV-RNA) (49 vs 8), etc. (Supplementary Table 2). Those with both hypertension and coronary heart disease (hypertension+coronary) had an increased correlation of RH blood group compared with the healthy cohort (41 vs 9 in normal). Conversely, the numbers of correlations in homocysteine (Hcy) were greatly reduced in unhealthy versus healthy patients (2 vs 120). In diabetes, 10 PEI pairs increased while the remaining 195 PEI pairs decreased; the increased PEIs including MON (41 vs 6), HCV-RNA (42 vs 8), anti-Sc70 (59 vs 31) and HCV-cAg (35 vs 10) (Supplementary Table 17). These results suggest that under the unhealthy status, the PEIs have changed systematically. Each disease has its own specific PEI spectrum.

We next explored the correlation networks among the PEIs using a qgraph ${ }^{8,10}$, which would show the LinkMode among PEIs. In the healthy status, we found that the PEIs showed rich interactions with both positive and negative directions (Fig. 3). In the unhealthy physical states, each of them showed its unique interaction networks with PEIs (Extended Data Figure 2 showed the network of hypertension and diabetes). These results show that there is a dependency relationship between multiple indicators in each physical state, which can be used with combination in the assessment of physical health.

\section{Candidate PEI markers for unhealthy physical status}


To verify and discovery new candidate biomarkers or the impact of living habits for disease early diagnosis, we next calculated the difference of each of the 221 PEIs between healthy and unhealthy physical states. In total, we found 1,239 significantly different PEI pairs between healthy and 34 unhealthy physical status $(P<0.05 / 34=0.0014$, adjust for 34 unhealthy physical status) (Table 1 , Fig. 4, Supplementary Table 36). For example, 112 PEIs were significantly different between patients with hypertension and healthy people, 100 PEIs were different between hypertension+diabetes and healthy people, and 91 PEIs were different between diabetes and the healthy people. Some of them are consistent with previous findings and the rest of them are newly discovered.

For many of the $221 \mathrm{PEI}$, we detected difference between healthy and unhealthy physical status, especially in PEIs involved in physique, lifestyles, blood lipids (Fig. 4, Supplementary Table 36). For example - BMI, we found differences between healthy and unhealthy physical status in 16 of the 34 unhealthy physical status, including in patients with hypertension $(P=0)$ and gout $\left(P=6.48 \times 10^{-90}\right)$. Exercise habits (E-habits) showed 19 differences between healthy and unhealthy status, including in hyperlipidemia $\left(P=1.28 \times 10^{-277}\right)$ and diabetes $\left(P=4.20 \times 10^{-29}\right)$. Dietary habits also showed differences in 10 unhealthy status, including in chronic pharyngitis $\left(P=2.59 \times 10^{-19}\right)$ and cholecystolithiasis $\left(P=9.43 \times 10^{-18}\right)$. We detected differences for alcohol intake habits in 20 unhealthy status, including hyperlipidemia $(P=0)$, coronary heart disease $\left(P=4.06 \times 10^{-24}\right)$, diabetes $\left(P=1.09 \times 10^{-22}\right)$ and Parkinson's syndrome $\left(P=1.43 \times 10^{-17}\right)$. We also observed differences for smoking habits in 18 unhealthy status when compared to the unhealthy condition, including in hypertension $\left(P=2.74 \times 10^{-114}\right)$, hyperlipidemia $\left(P=2.69 \times 10^{-62}\right)$ and Parkinson's syndrome $\left(P=5.12 \times 10^{-29}\right)$. We found differences for IOP-R in five unhealthy status compared with healthy, including in hypertension $\left(P=3.63 \times 10^{-85}\right)$ and diabetes $\left(P=2.01 \times 10^{-73}\right)$; similar findings were produced for IOP-L (Fig. 4, Supplementary Table 36). For lipids PEIs, we also observed differences between 34 unhealthy and healthy status. For example, LDL-C was detected in 21 unhealthy status, including hypertension $(P=0)$ and diabetes $\left(P=2.95 \times 10^{-212}\right)$. HDL-C was detected in 17 unhealthy status, including in diabetes $\left(P=1.92 \times 10^{-177}\right)$ (Fig. 4, Supplementary Table 36). We further conducted a detailed analysis of HDL-C and diabetes and found those with low HDL-C showed a significantly higher risk of developing diabetes than those with average values (1.26-1.75 mmol/L) in this population. Of note, those with high HDL-C levels also showed elevated risk of developing diabetes (Extended data Fig. 2). 
Tumor-associated antigens also display significant differences between the healthy and unhealthy status. For example, CYFRA 21-1 was detected in 10 unhealthy status, including hypertension+diabetes $\left(P=3.71 \times 10^{-97)}\right.$ and diabetes $\left(P=4.52 \times 10^{-70}\right)$. CEA1 was detected in 12 unhealthy status, including hypertension+coronary $\left(P=9.59 \times 10^{-29}\right)$ and diabetes $\left(P=1.73 \times 10^{-18}\right)$. Alpha-fetoprotein (AFP) was detected in hepatopathy $\left(P=1.08 \times 10^{-28}\right)$. C-PSA was detected in hypertension+coronary $\left(P=8.38 \times 10^{-20}\right)$. Finally, the carbohydrate antigen CA724 (CA 72-4) was detected in asthma $\left(P=9.92 \times 10^{-13}\right)$, gout $\left(P=3.53 \times 10^{-7}\right)$ and coronary+diabetes $\left(P=4.06 \times 10^{-5}\right)($ Fig. 4, Supplementary Table 36). Among other PEIs, we also detected significant differences between the healthy and unhealthy status. For example, we found differences in urine sugar levels (U-GLU) in nine unhealthy status, including in diabetes and its associated diseases. The eosinophil rate (eo\%), was found in five unhealthy status, including asthma $\left(P=1.38 \times 10^{-129}\right)$ and rhinallergosis $\left(P=4.05 \times 10^{-18}\right)$. Whole blood iron levels (WB-Fe) was found in 11 unhealthy status, including hypertension $\left(P=2.52 \times 10^{-69}\right)$. We detected $\mathrm{PH}$ in 11 unhealthy status, including diabetes $\left(P=1.97 \times 10^{-239}\right)$, hypertension $\left(P=2.41 \times 10^{-166}\right)$, hypertension+diabetes $\left(P=9.90 \times 10^{-32}\right)$ and gout $\left(P=9.82 \times 10^{-15}\right)$. We found potassium $(\mathrm{K}+)$ in five unhealthy status, including hypertension $\left(P=1.98 \times 10^{-119}\right)$ and hepatitis $\mathrm{B}\left(P=3.13 \times 10^{-10}\right)$. We also detected differences in magnesium $(\mathrm{Mg} 2+)$ in hypertension+diabetes $\left(P=3.14 \times 10^{-58}\right)$ and diabetes $\left(P=5.10 \times 10^{-52}\right)$. Hcy (an indicator of cardiovascular disease) was detected in eight unhealthy status, including hypertension $\left(P=1.97 \times 10^{-136}\right)$ and Parkinson's syndrome $\left(P=1.76 \times 10^{-7}\right)$ (Fig. 4, Supplementary Table 36). These results provide a set of candidate markers for chronic diseases early diagnosis.

\section{Machine learning to predict healthy and unhealthy physical status from PEIs}

A key objective of this study was to apply PEI data and machine learning technology to develop algorithms that can predict the onset of common disease based on general physical examination. We tried three machine learning models, including kernelized support vector machine (SVM), multilayer perceptron (MLP) and random forests. Because SVM and MLP prediction models only gave very low accuracy and sensitivity in our initial training data, we excluded these models for further training. Random forests showed better performance than SVM and MLP in the initial training. However, it could not give good performance in the multi-class classification of all the physical status. Finally, we 
tried to use binary classification to classify each pair of healthy and unhealthy physical status (e.g. hypertension and healthy people; Parkinson's syndrome and healthy people) and we obtained relatively better performance than the multi-class classification. Then we tried to optimize this prediction algorithm. Because the data were characterized by serious category imbalance, a random under-sampling method, was adopted that balances the data by randomly selecting the data subset of the target class. In each physical status, the top $15 \%$ or $16 \%$ representative PEIs were extracted for prediction by feature extraction. The advantage of this method is that it is usually very fast and completely independent of the model applied after feature selection.

Finally, in the random forests algorithm prediction of each pair of healthy and unhealthy physical status, the area under curve (AUC) of receiver operating characteristic curve reached 66\% 99\% depending on the unhealthy physical status (average 87.6\%) (Fig.5, Extended data Table 2, Extended data Table 3 and Supplementary Table 37). For classification, AUC values more than $90 \%$ indicated excellent performance, and values from $80 \%$ to $90 \%$ indicated good performance. Our algorithm provided high-precision predictions in 18 of the 34 unhealthy physical status (AUC>90\%), good performance for another 9 of the unhealthy physical status $(90 \%>$ AUC $>80 \%)$. In our algorithm, patients with heart-related diseases showed excellent performance. For example, by extraction 30 PEI features (age, leukocyte count, monocytes, Mon\%, mean corpuscular volume, red blood cell count, red cell distribution width, lymphocyte rate, platelet count, low-density lipoprotein, high-density lipoprotein, total cholesterol, carcinoembryonic antigen 1, albumin, albumin-globulin, cystatin c, glucose, urine sugar, urine creatinine, estimated glomerular filtration rate, creatinine, urea, waistline, aaist-hip Ratio, body mass index, operation history, systolic pressure, height, neck size and anamnesis, Extended data Table 2), Hypertensive+Diabetes+Coronary Heart Disease provides 99\% AUC just using 909 training samples and 387 validation samples (f1-score (95\%CI), 0.96(0.95-0.96); accuracy (95\%CI): 0.95(0.94-0.97); specificity (95\%CI): 0.95(0.94-0.95); recall (sensitivity) (95\%CI): 0.95(0.94-0.97). In our algorithm, patients with Parkinson's syndrome provides 97\% AUC using 192 training samples and 83 validation samples (f1-score (95\%CI), 0.91(0.90-0.91); accuracy (95\%CI): 0.90(0.89-0.90); specificity (95\%CI): 0.87(0.79-0.94); recall (95\%CI): 0.90(0.89-0.91). For hepatic adipose infiltration, our algorithm also provided good prediction performance using 803 training samples and 115 validation samples (f1-score (95\%CI), 0.82(0.78-0.87); accuracy (95\%CI): 0.81(0.76-0.86) ; 
specificity (95\% CI): 0.75(0.67-0.82); recall (95\% CI): 0.82(0.77-0.87) and AUC (95\% CI):

0.92(0.89-0.94). For chronic rhinitis, we got the lowest prediction performance in this study (AUC(95\%CI):0.66(0.60-0.72)). When all unhealthy physical status were classified as one "unhealthy" status together, our algorithm also provided good predictions: f1-score (95\%CI): 0.83 (0.83-0.83); accuracy (95\%CI): 0.82 (0.82-0.82); specificity (95\%CI): 0.81(0.81-0.81); sensitivity (95\%CI): 0.84 (0.84-0.84) and AUC (95\%CI): 0.9 (0.90-0.90). These results suggested that by using feature extraction of the PEIs (15-16\% of all 221 PEIs) just by using small number of samples, our random forests algorithms provided good performance for majority unhealthy physical status predictions.

\section{Discussion}

This study has produced correlation maps of 221 routine PEIs using physical examination data obtained from a Chinese population of 803,614 individuals of 35 healthy or unhealthy physical status (mainly chronic diseases). We detected a large number of correlations among PEIs in healthy or unhealthy physical states; furthermore, these correlations differed according to the 34 unhealthy physical conditions analyzed. Most of the correlations are newly observed in this study. We found that a wide range of correlations among PEIs, such as sex, age, BMI, blood lipids, blood pressures, cancer-related indicators, lifestyles including drinking, smoking, e-habits. Improving our understanding these PEI interactions will help explain disease mechanisms and pathogenesis. Our results fill the gap of systematic PEI analysis and provide rich information about how PEIs might reflect underlying health conditions. These findings provide rich information to further improve healthcare researches and clinical practice.

One of the unexpected finding from our analysis was that patients with hypertension showed more correlations between HBV-DNA and HCV-RNA to other PEIs than healthy cohort. Similarly, we found a strong correlation between hepatitis C virus and other PEIs in diabetes, suggesting that patients infected with hepatitis $\mathrm{C}$ may be more susceptible to diabetes. This finding implicates a phenomenon whereby viral infection can make an individual more susceptible to developing a chronic disease. For these people, antiviral therapy might be taken into consideration while treating hypertension and diabetes. 
Biomarker discovery and development for clinical research, diagnostics and therapy monitoring in clinical trials are key areas of medicine and healthcare ${ }^{6}$. In this study, we presented many candidate markers for chronic disease. For example, we found that IOP indicators, which are considered to be a relatively independent marker for glaucoma ${ }^{20}$, are closely associated to hypertension, diabetes, and hypertension with diabetes. These results suggest that IOP might be affected, to some extent, by systemic diseases and might be used as one of the clinical marker of these diseases early diagnosis. Our results confirmed that low HDL-C level is a risk factor for diabetes ${ }^{21}$, especially in women. This result suggests that improving HDL-C level through dietary supplementation might be an effective way to prevent diabetes in patients with low HDL-C levels. However, based on our results, excessive HDL-C supplementation is also a risk factor; therefore, HDL-C supplementation should aim to bring HDL-C levels within a normal range ${ }^{22}$. We detected a significant increase in AFP in hepatopathy when comparing healthy cohort, which confirms AFP increase is an increased risk factor for primary liver cancer in hepatopathy ${ }^{14-15} \cdot \mathrm{K}^{+}$has significant effects on hypertension ${ }^{23}$ and $\mathrm{Cl}^{-}$, and $\mathrm{Mg}^{2+}$ has significant effects on diabetes, suggesting that modulation of these ions might have effects on these conditions. Living habits, such as exercise, smoking and drinking, have a more profound impact on the body than we had expected. For example, exercise, drinking or smoking history have a strong impact on hyperlipidemia ${ }^{24-25}$, as evidenced by comparision to healthy status. This finding suggests that by adjusting these living habits, hyperlipidemia should improve.

Because the current physical examination conclusion is generally based on a relatively independent single or several prior indicators to give advice on the results of physical examination, many of the results given are ambiguous, and the value of judging the health status of the examinees is very limited $^{10,26-27}$. There is an urgent need for a more accurate index system and method to judge the health status of physical examinees. In the final part of our study, we developed random forest machine learning algorithms that can predict diseases through 15\%-16\% of all 221 PEIs with good performance of prediction (AUC:66\% 99\%; average 86\%). For each disease, we defined about 30 contributed PEIs by feature extraction. In most of our prediction algorithms, only a few hundreds of samples were needed to give good prediction performance for many chronic diseases. This finding suggests machine learning on PEI data can be used to help predict the true condition of the examers, identify "at-risk" patients and indicate the most relevant follow-up physical examinations for affected individuals. 
In summary, we systematically explored the correlation between various PEIs and their relationship with chronic diseases and established machine learning prediction models to predict health status. This study provides abundant information to better understand the physiological and pathological characteristics of the human body as a system. Importantly, we have identified modifiable factors and directions for disease prediction, diagnosis and treatment. Our developed machine learning algorithms can be immediately applied to clinical practice to assistant the judgment of physical examination results.

\section{Methods}

\section{Study approval}

The study was approved by the institutional ethics committee of Sichuan Provincial People's Hospital and was conducted according to the Declaration of Helsinki principles. Informed consent was obtained from the participants when possible.

\section{Study Participants}

PEI data were obtained from 803,614 Han Chinese patients visiting the Health Management Center \& Physical Examination Center of Sichuan Provincial People's Hospital in China between 2013 and 2018. The total cohort captured participants with 35 different reported health conditions, including 711,928 reported healthy participants and 91,686 unhealthy participants. The unhealthy cohort included 46,981 patients with hypertension, 11,745 with diabetes and 32,960 with other unhealthy status (Table 1).

\section{Detected PEIs}

Only the PEIs that were recorded by the same methods were included in this study. In total, 229 PEIs were initially collected: eight PEIs that were detected in few individuals were excluded, leaving 221 PEIs for further analysis (Extended data Table 1). These PEIs included the levels of biochemical indicators and the results of blood tests. Patient lifestyles and disease conditions were also investigated during the physical examination.

\section{Data processing}

The PEIs with string variables were converted to integer variables for data analysis. Categorized variables were digitally coded for further calculation. The mean value imputation method was used for missing data. For individuals who participated in more than one physical check, average values of each PEI were used for data analysis. 


\section{Statistical Analyses}

The Pearson correlation coefficient (PCC) method was used to calculate the correlations between two PEIs (for example, $\mathrm{x}$ and $\mathrm{y}$ ) in $\mathrm{R}$; this method measures the linear dependence between two variables. PCC correlation (r) (1) and $P$ values (2) were calculated using the following formulae $e^{28-30}$ :

(1)

$$
r=\frac{\mathrm{n}\left(\sum \mathrm{xy}\right)-\left(\sum \mathrm{x}\right)\left(\sum \mathrm{y}\right)}{\sqrt{\left[\mathrm{n} \sum \mathrm{x}^{2}-\left(\sum \mathrm{x}\right)^{2}\right]\left[\mathrm{n} \sum \mathrm{y}^{2}-\left(\sum \mathrm{y}\right)^{2}\right]}}
$$

$$
\begin{aligned}
& P=1-\text { F.DIST }\left(\left((\mathrm{n}-2) * \mathrm{r}^{\wedge} 2\right) /\left(1-\mathrm{r}^{\wedge} 2\right), 1, \mathrm{n}-2\right) \\
& \mathrm{df}=\mathrm{n}-2 \\
& \mathrm{n}=\text { number of } \mathrm{x}-\mathrm{y} \text { data pairs }
\end{aligned}
$$

Total sample size required when using the correlation coefficient (r), when two-sieded $\alpha=0.05, \beta=0.20$. If $\mathrm{r}=0.05$, we need 3,134 samples; if $\mathrm{r}=0.10$, we need 782 samples; if $\mathrm{r}=0.25$, we need 123 samples; if $\mathrm{r}=0.5$, we need 29 samples. The general formula for the correlation sample calculating is listed as the following $(3)^{31}$ :

$$
\begin{aligned}
& r=\text { expected correlation coefficient } \\
& C=0.5 \times \ln [(1+\mathrm{r}) /(1-\mathrm{r})] \\
& N=\text { Total number of subjects required } \\
& \text { Then } \\
& N=\left[\left(Z_{\alpha}+Z_{\beta}\right) \div \mathrm{C}\right] 2+3 .
\end{aligned}
$$

A linear regression model ( $\mathrm{lm}$ ) was used to compare PEIs between the reported healthy status and unhealthy status adjusted for sex and age in the R package ${ }^{21-23}$. The odds ratio of HDL-C level was calculated by using generalized linear models (glm) adjusted for age in the R package ${ }^{24-25}$. The correlation interaction network was conducted using qgraph ${ }^{10-11}$.

\section{Machine learning}

Three machine learning models, including kernelized support vector machine (SVM) ${ }^{28-29}$, multilayer perceptron (MLP) $)^{30-32}$ and random forest ${ }^{33}$ were tested to get the prediction performance of the PEIs. By using MLP algorithm prediction in neural network to predict health and each of the 34 unhealthy status (multi classification), it could not achieve good results. We further tried prediction the healthy from each unhealthy statues by the binary classification method, the F1 value of the prediction each 
result is very close to zero. By using SVM algorithm prediction for making multi classification prediction, the highest $\mathrm{F} 1$ value of cholecystolithias is 0.70 , but that of most other types of diseases is 0.00. We also tried the binary classification method, but all the results were relatively poor. When random forest algorithm is used for prediction for multi classification (health and each of the 34 unhealthy status), the F1 value of healthy status can reach $0.80-0.90$, but the F1 value of unhealthy sattus is about $0.00-0.40$. Then, we further chosen forest algorithm and optimized the random forest algorithm. First, due to the uneven distribution of the sample numbers of healthy and non-healthy status, and the law of large numbers ${ }^{32}$, we used downsampling strategy for sample randomly used. Because the data were characterized by serious category imbalance, a random under-sampling method, was adopted that balances the data by randomly selecting the data subset of the target class. Second, we used PEI feature extraction strategy to extract the most contributed PEI for each healthy and unhealthy status. Feature extraction adopts the strategy of univariate statistics in automatic feature selection. Univariate statistics select features with high confidence according to the statistical significance of the relationship between each feature and the target. This process can be achieved by using feature_selection in scikit-learn. Finally, in each healthy and non-healthy status, the top $15 \%$ or $16 \%$ representative PEIs were extracted for prediction by feature extraction. The advantage of this method is that it is usually very fast and completely independent of the model applied after feature selection. Then, the data were randomly divided such that $30 \%$ constituted the test set, and the remaining $70 \%$ were randomly divided again, with $70 \%$ as the training set for the training model and $30 \%$ as the validation set for the evaluation model. In the process of improving the generalization performance of the model by adjusting parameters, a cross-validation method with a grid search was adopted, which can be implemented by GridSearchCV provided by scikit-learn (Supplementary Table 37 and Supplementary code). 


\section{References}

1 Steenhuis, S., Groeneweg, N., Koolman, X. \& Portrait, F. Good, better, best? A comprehensive comparison of healthcare providers' performance: An application to physiotherapy practices in primary care. Health Policy 121, 1225-1232, doi:S0168-8510(17)30274-9 [pii], 10.1016/j.healthpol.2017.09.021 (2017).

2 Liu, Q., Tian, X., Tian, J. \& Zhang, X. Evaluation of the effects of comprehensive reform on primary healthcare institutions in Anhui Province. BMC Health Serv Res 14, 268, doi:1472-6963-14-268 [pii, 10.1186/1472-6963-14-268 (2014).

3 Perry, H. B., Shanklin, D. S. \& Schroeder, D. G. Impact of a community-based comprehensive primary healthcare programme on infant and child mortality in Bolivia. $J$ Health Popul Nutr 21, 383-395 (2003).

4 Lennox, N. G., Green, M., Diggens, J. \& Ugoni, A. Audit and comprehensive health assessment programme in the primary healthcare of adults with intellectual disability: a pilot study. J Intellect Disabil Res 45, 226-232, doi:jir303 [pii] (2001).

5 Mills, A. Health care systems in low- and middle-income countries. The New England journal of medicine 370, 552-557, doi:10.1056/NEJMra1110897 (2014).

6 Keenan, G. M. Big Data in Health Care: An Urgent Mandate to CHANGE Nursing EHRs! On-line journal of nursing informatics 18 (2014).

7 van Ginneken, E. Perennial Health Care Reform--The Long Dutch Quest for Cost Control and Quality Improvement. The New England journal of medicine 373, 885-889, doi:10.1056/NEJMp1410422 (2015).

8 Krogsboll, L. T., Jorgensen, K. J. \& Gotzsche, P. C. General health checks in adults for reducing morbidity and mortality from disease. The Cochrane database of systematic reviews 1, CD009009 (2019).

9 Frieden, T. R. SHATTUCK LECTURE: The Future of Public Health. The New England journal of medicine 373, 1748-1754, doi:10.1056/NEJMsa1511248 (2015).

10 Goroll, A. H. Toward Trusting Therapeutic Relationships--In Favor of the Annual Physical. The New England journal of medicine 373, 1487-1489, doi:10.1056/NEJMp1508270 (2015).

11 Krogsboll, L. T., Jorgensen, K. J., Gronhoj Larsen, C. \& Gotzsche, P. C. General health checks in adults for reducing morbidity and mortality from disease: Cochrane systematic review and meta-analysis. Bmj 345, e7191, doi:10.1136/bmj.e7191 (2012).

12 Vigilante, K., Escaravage, S. \& McConnell, M. Big Data and the Intelligence Community Lessons for Health Care. The New England journal of medicine 380, 1888-1890 (2019).

13 Anoushiravani, A. A., Patton, J., Sayeed, Z., El-Othmani, M. M. \& Saleh, K. J. Big Data, Big Research: Implementing Population Health-Based Research Models and Integrating Care to Reduce Cost and Improve Outcomes. The Orthopedic clinics of North America 47, 717-724, doi:10.1016/j.ocl.2016.05.008 (2016).

14 Obermeyer, Z. \& Emanuel, E. J. Predicting the Future - Big Data, Machine Learning, and Clinical Medicine. The New England journal of medicine 375, 1216-1219, doi:10.1056/NEJMp1606181 (2016).

15 Ngiam, K. Y. \& Khor, I. W. Big data and machine learning algorithms for health-care 
delivery. The Lancet. Oncology 20, e262-e273, doi:10.1016/S1470-2045(19)30149-4 (2019).

16 Beam, A. L. \& Kohane, I. S. Big Data and Machine Learning in Health Care. Jama 319, 1317-1318 (2018).

17 Pazzani, M. J., Mani, S. \& Shankle, W. R. Acceptance of rules generated by machine learning among medical experts. Methods Inf Med 40, 380-385, doi:01050380 [pii] (2001).

18 Kononenko, I. Machine learning for medical diagnosis: history, state of the art and perspective. Artif Inte/l Med 23, 89-109, doi:S0933-3657(01)00077-X [pii] (2001).

Yip, W. \& Hsiao, W. Harnessing the privatisation of China's fragmented health-care delivery. Lancet 384, 805-818, doi:S0140-6736(14)61120-X [pii], 10.1016/S0140-6736(14)61120-X (2014).

Sultan, M. B., Mansberger, S. L. \& Lee, P. P. Understanding the importance of IOP variables in glaucoma: a systematic review. Surv Ophthalmol 54, 643-662, doi:S0039-6257(09)00116-7 [pii], 10.1016/j.survophthal.2009.05.001 (2009).

21 Schmidt, M. I. et al. Identifying individuals at high risk for diabetes: The Atherosclerosis Risk in Communities study. Diabetes Care 28, 2013-2018, doi:28/8/2013 [pii], 10.2337/diacare.28.8.2013 (2005).

22 Borggreve, S. E., De Vries, R. \& Dullaart, R. P. Alterations in high-density lipoprotein metabolism and reverse cholesterol transport in insulin resistance and type 2 diabetes mellitus: role of lipolytic enzymes, lecithin:cholesterol acyltransferase and lipid transfer proteins. Eur J Clin Invest 33, 1051-1069 (2003).

Diness, J. G. et al. Effects on atrial fibrillation in aged hypertensive rats by $\mathrm{Ca}(2+)$-activated $\mathrm{K}(+)$ channel inhibition. Hypertension 57, 1129-1135, doi:HYPERTENSIONAHA.111.170613 [pii], 10.1161/HYPERTENSIONAHA.111.170613 (2011).

Chanoine, P. \& Spector, N. D. Hyperlipidemia, eating disorders, and smoking cessation. Curr Opin Pediatr 20, 734-739, doi:10.1097/MOP.0b013e32831a6bed, 00008480-200812000-00021 [pii] (2008).

25 Saito, Y. Secondary hyperlipidemia due to obesity and alcohol drinking. Nihon Naika Gakkai Zasshi 81, 1784-1787 (1992).

Mehrotra, A. \& Prochazka, A. Improving Value in Health Care--Against the Annual Physical. The New England journal of medicine 373, 1485-1487, doi:10.1056/NEJMp1507485 (2015).

27 Donabedian, A. Evaluating the quality of medical care. 1966. Milbank Q 83, 691-729, doi:MILQ397 [pii],10.1111/j.1468-0009.2005.00397.x (2005).

28 Brown, B. W., Jr., Lucero, R. J. \& Foss, A. B. A situation where the Pearson correlation coefficient leads to erroneous assessment of reliability. J Clin Psycho/ 18, 95-97 (1962).

Haldar, P. et al. Cluster analysis and clinical asthma phenotypes. Am J Respir Crit Care Med 178, 218-224 (2008).

30 Kew, M. Alpha-fetoprotein in primary liver cancer and other diseases. Gut 15, 814-821 (1974).

31 Hulley S.B, C. S. R., Browner W.S, Grady D, Newman T.B. . Designing clinical research : an epidemiologic approach. 4th ed. . Philadelphia, PA: Lippincott Williams \& Wilkins; 2013. 
bioRxiv preprint doi: https://doi.org/10.1101/855809; this version posted November 26, 2019. The copyright holder for this preprint (which was not certified by peer review) is the author/funder, who has granted bioRxiv a license to display the preprint in perpetuity. It is made available under aCC-BY-NC-ND 4.0 International license.

Appendix 6C, page 79. (2013).

32 Laurikkala, J. P., Kentala, E. L., Juhola, M. \& Pyvkko, I. V. A novel machine learning program applied to discover otological diagnoses. Scand Audio/ Suppl, 100-102 (2001). 


\section{ACKNOWLEDGMENTS}

We thank all the participants in this study. This research project was supported by: the National Natural

Science Foundation of China (81970839(L.H.), 81670895 (L.H.) and 81300802 (L.H.); the Department of Science and Technology of Sichuan Province, China (2015JQO057 (L.H.), 2017JQ0024 (L.H.),

2016HH0072 (L.H.) and 2013JY0195 (L.H.); the Department of Science and Technology of Sichuan Province, China (2017JZ0039 (P.S.). The author is especially indebted to Dr. Yabing Mei for taking time to make extensive comments.

\section{AUTHOR CONTRIBUTIONS}

L.H. designed the study. P.S., Y.L., L.J., J.Y., S.Z., Y.Y., L.W., D.L. and T.Y. enrolled all the participants. L.H., H.W. and P.S. performed the data analysis. Y.D., S.Z. and Y.Y., did the machine learning prediction models. L.H. wrote the manuscript. All of authors critically revised and provided final approval for this manuscript.

\section{COMPETING FINANCIAL INTERESTS}

The authors declare no competing interests related to this paper. 
Table 1. Summary of the study samples, detected correlations and the different PEIs between healthy status and unhealthy states

\begin{tabular}{|c|c|c|c|c|c|c|}
\hline Body status & Sample (N) & Age (Range) & Female $\%$ & Sig. Correlation (a) & Sig. Correlation \% (b) & Different PEIs (c) \\
\hline Normal condition & 711928 & $41.4(4 \sim 105)$ & 45.7 & 7662 & 31.5 & - \\
\hline Cholecystolithiasis & 993 & $50.09(19 \sim 97)$ & 47.8 & 1622 & 6.9 & 28 \\
\hline Hypertension & 46981 & $62.0(20 \sim 102)$ & 36.1 & 4413 & 18.3 & 112 \\
\hline Hypertension+Diabetes & 8586 & $67.3(34 \sim 99)$ & 67.1 & 3008 & 12.6 & 100 \\
\hline Hypertension+Coronary & 2074 & 74.0(34 98) & 40.4 & 1920 & 7.7 & 53 \\
\hline Hypertensive+Diabetes+Coronary & 928 & 73.5(37 98) & 35 & 2014 & 8.7 & 56 \\
\hline Hyperlipidemia & 1722 & 65.0(29 96) & 33 & 2256 & 9.5 & 51 \\
\hline Coronary heart disease & 1325 & 68.7(27 93) & 24.6 & 1925 & 8.3 & 36 \\
\hline Coronary+Diabetes & 280 & $70(44 \sim 89)$ & 20.4 & 1335 & 6.2 & 40 \\
\hline Rhinallergosis & 156 & $39(18 \sim 92)$ & 39.7 & 1278 & 6.1 & 12 \\
\hline Hypothyroidism & 1661 & 46.7(16 94) & 84.6 & 1703 & 7.1 & 33 \\
\hline Hyperthyroidism & 767 & $45.2(15 \sim 89)$ & 66.6 & 1234 & 5.2 & 16 \\
\hline Cervical spondylopathy & 318 & $53.7(27 \sim 87)$ & 48.7 & 1589 & 7 & 14 \\
\hline Rheumatoid arthritis & 396 & $55.0(24 \sim 86)$ & 74.7 & 1039 & 4.5 & 29 \\
\hline Chronic rhinitis & 320 & $38.6(21 \sim 85)$ & 30.6 & 969 & 4.5 & 8 \\
\hline Nephropathy & 76 & $48.6(23 \sim 91)$ & 42 & 1771 & 7.8 & 31 \\
\hline Diabetes & 11745 & 59.3(14 96) & 24.9 & 2972 & 12.3 & 91 \\
\hline Gout & 2138 & $51.8(20 \sim 97)$ & 2 & 1813 & 7.8 & 52 \\
\hline Parkinson's syndrome & 197 & $70.4(40 \sim 92)$ & 26.4 & 1659 & 8.1 & 28 \\
\hline Stomach trouble & 1296 & 49.5 (19 95) & 39.2 & 1523 & 6.5 & 37 \\
\hline Chronic pharyngitis & 782 & $40.2(18 \sim 90)$ & 32.7 & 1487 & 6.2 & 14 \\
\hline Lumbar disc protrusion & 385 & $56.8(25 \sim 91)$ & 35.6 & 982 & 4.3 & 12 \\
\hline Hepatitis B & 706 & $45.3(22 \sim 82)$ & 22.8 & 1084 & 4.5 & 34 \\
\hline Hypertension+other diseases & 2409 & 64.6（28 94） & 38.1 & 1750 & 7.1 & 67 \\
\hline
\end{tabular}




\begin{tabular}{|c|c|c|c|c|c|c|}
\hline Coronary+others & 101 & 69.3(36 92) & 33.7 & 569 & 3.3 & 12 \\
\hline Diabetes+others & 373 & $63(29 \sim 90)$ & 26.8 & 1045 & 4.6 & 35 \\
\hline Bronchial disease & 574 & $60.7(19 \sim 95)$ & 33.2 & 1276 & 5.6 & 19 \\
\hline Other disease conditions & 2777 & $51.4(17 \sim 100)$ & 43.8 & 2066 & 8.5 & 38 \\
\hline Brain diseases & 257 & $69.9(27 \sim 98)$ & 29.5 & 1023 & 4.7 & 25 \\
\hline Hepatic adipose infiltration & 274 & $44.1(21 \sim 77)$ & 12.4 & 1139 & 5.3 & 36 \\
\hline Asthma & 280 & $51.0(12 \sim 91)$ & 57.9 & 1388 & 5.9 & 23 \\
\hline Other Cardiac diseases & 344 & $60.0(26 \sim 90)$ & 55.9 & 749 & 3.6 & 19 \\
\hline Heart disease & 229 & $69.7(26 \sim 96)$ & 42.6 & 698 & 3.5 & 28 \\
\hline Hepatopathy & 180 & $51.6(25 \sim 83)$ & 38.7 & 702 & 3.6 & 25 \\
\hline Pregnant & 56 & $29.7(24 \sim 36)$ & 100 & 1015 & 8.5 & 25 \\
\hline
\end{tabular}

(a) Significant correlations, the number of correlations with $P$ values calculated by PCC adjusted by all the correlations $\left(P<0.05 / 24,322\right.$ PEI pairs $\left.=2 \times 10^{-6}\right)$,

(b) Significant correlation $\%$, which is the percentage of significant correlations in all the correlation pairs.

Detailed information on the correlations described in (a-b) is provided in Supplementary Table 1-35.

(c) The number of PEIs was significantly different between normal physical status and nonnormal physical states $\left(P<0.05 / 34\right.$ nonnormal states $\left.=1.4 \times 10^{-3}\right)$. A linear regression model $(\mathrm{lm})$ was used to compare PEIs between normal physical status and nonnormal physical states adjusted for gender and age. Detailed information for this summary is provided in Supplementary Table 36. 
bioRxiv preprint doi: https://doi org/101101/855809; this version posted November 26, 2019. The copyright holder for this preprint (which was not certified by peer review) is the author/funder, who has granted bioRxiv a license to display the preprint in perpetuity. It is made available under aCC-BY-NC-ND 4.0 International license.

Figure legends:

Figure 1. The PEI correlations detected in the healthy cohort. a, A correlation map of the top 50 correlated PEIs, each of which had $>114$ significant correlations with other PEIs (FDR $<0.05)$. b, The number of statistically significant correlations detected in the healthy population of each PEI.

a

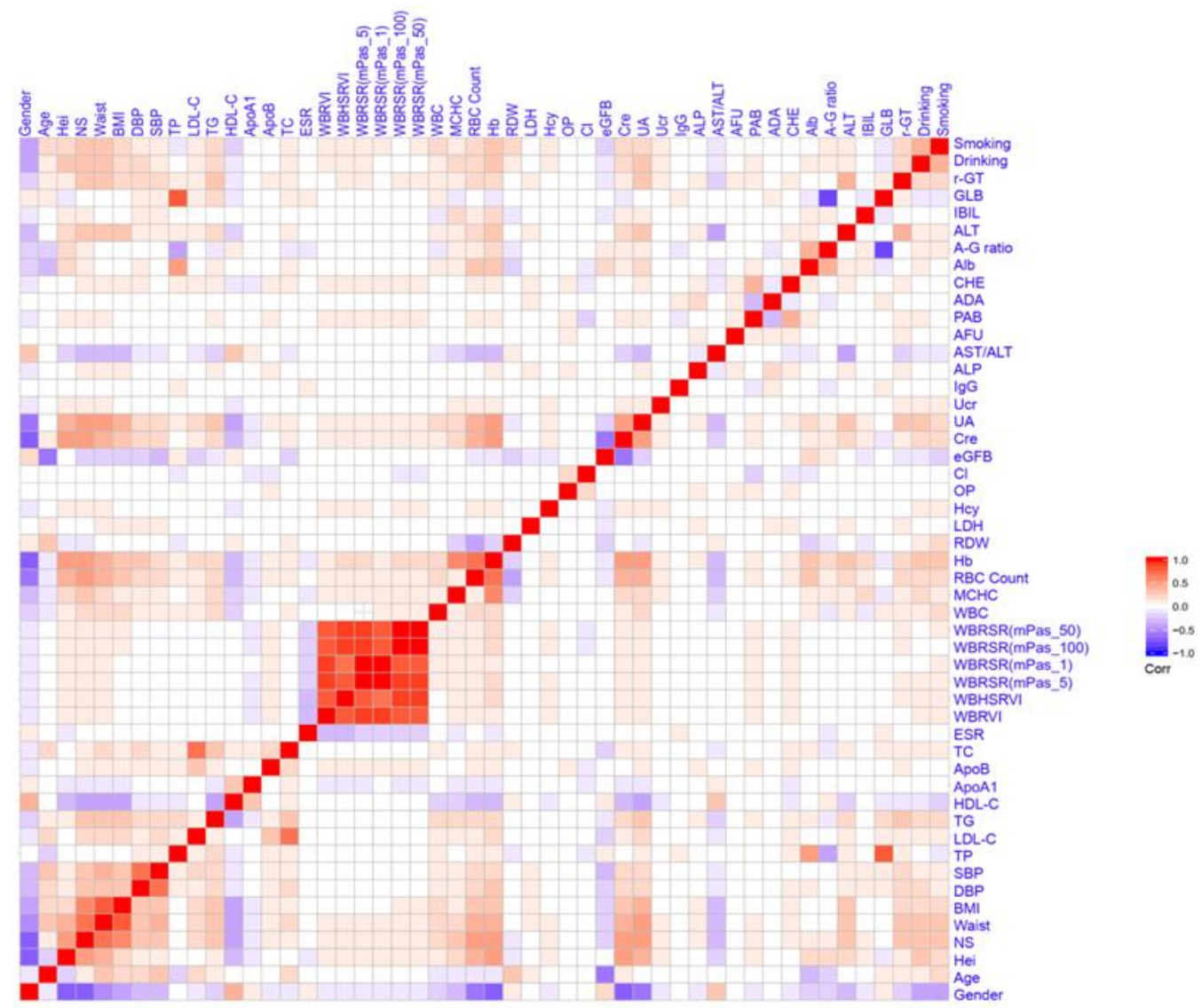

b
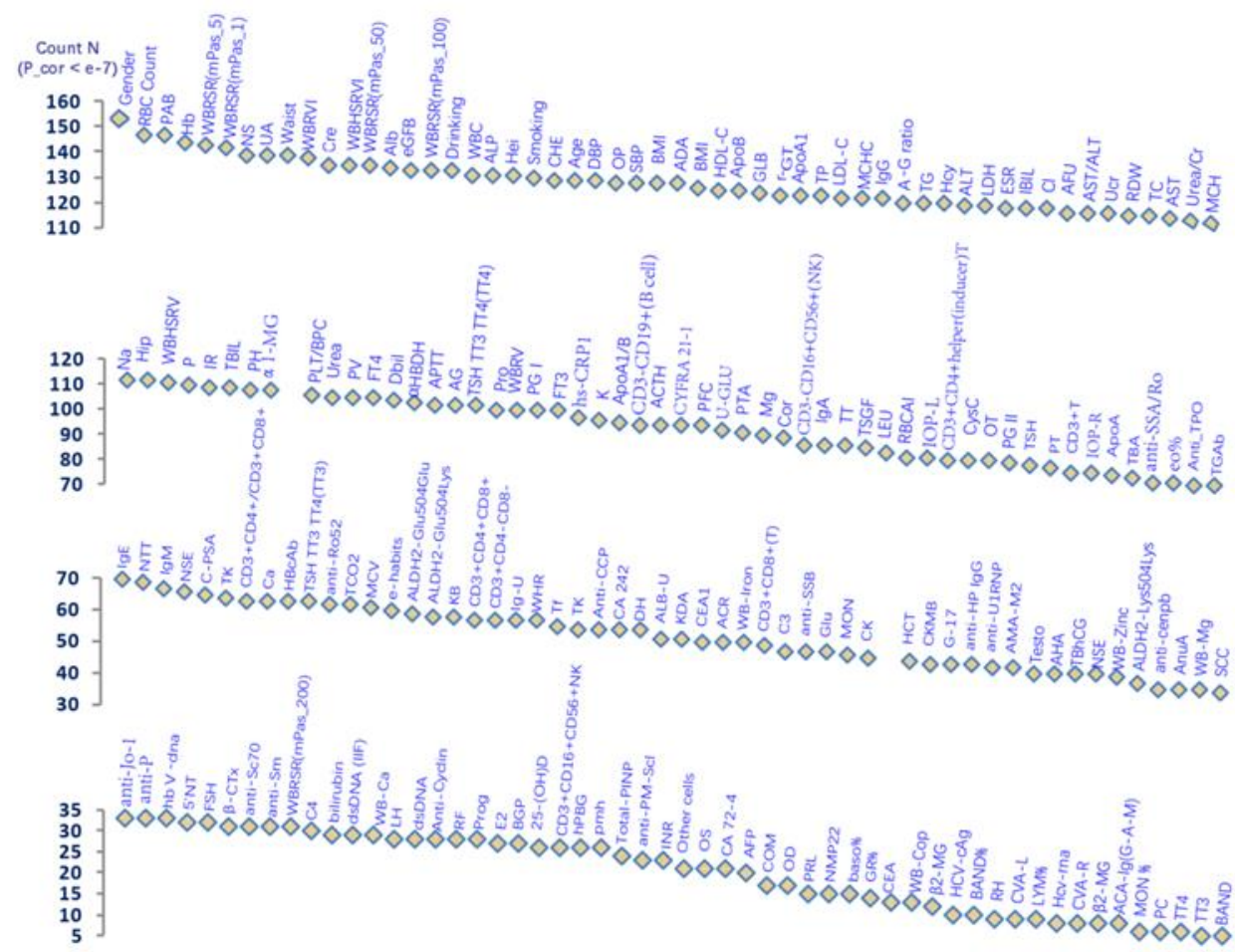
Figure 2. The correlation directions of typical PEIs in healthy physical conditions. The $r$ values were calculated by the PCC method. See Extended data Table 1 for detailed PEI information.

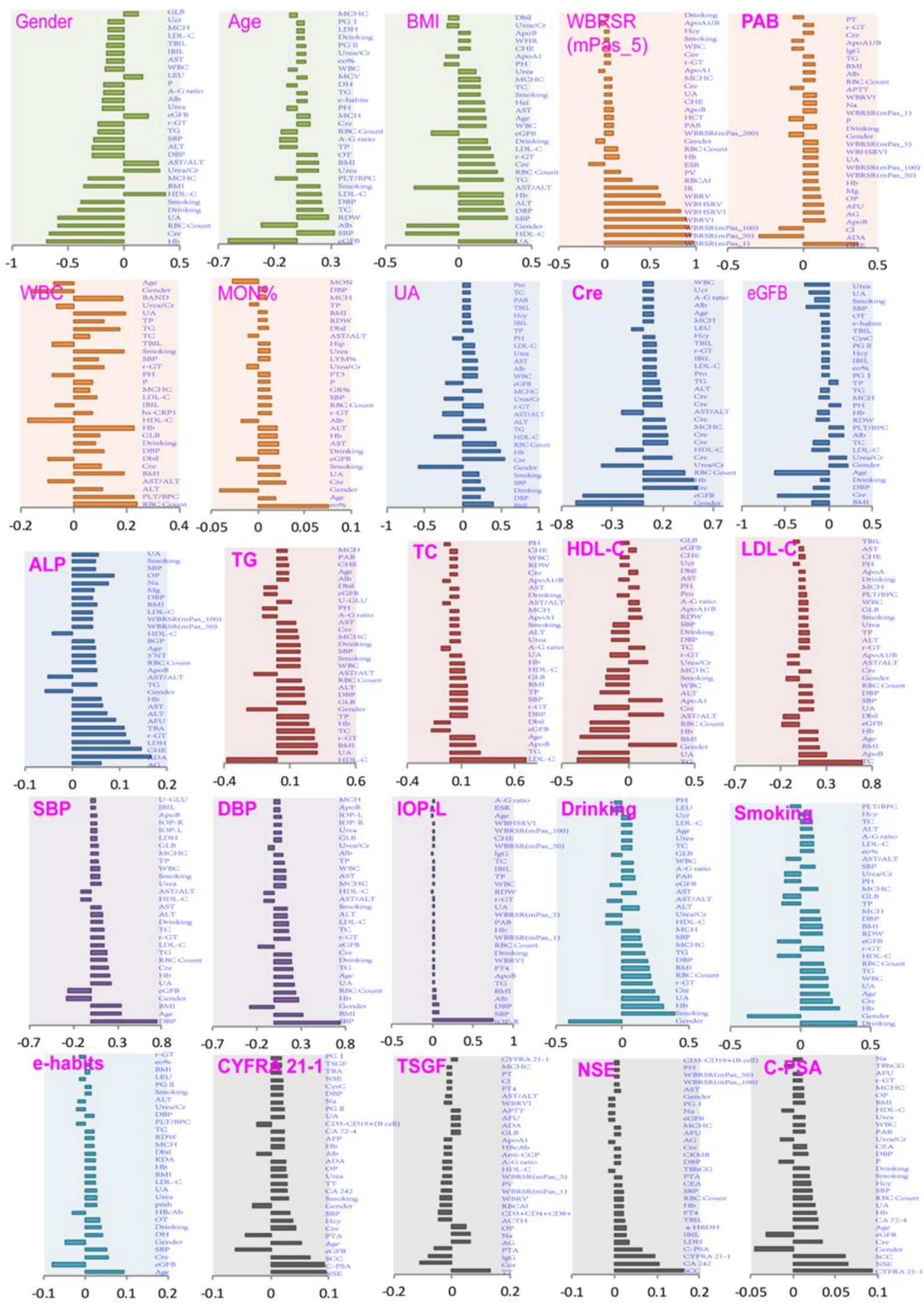


bioRxiv preprint doi: https://doi org/10.1101/855809; this version posted November 26, 2019. The copyright holder for this preprint (which was not certified by peer review) is the author/funder, who has granted bioRxiv a license to display the preprint in perpetuity. It is made available under aCC-BY-NC-ND 4.0 International license.

Figure 3. PEI networks in healthy physical status. In the weighted graphs, the green edges indicate positive weights, and the red edges indicate negative weights. The color saturation and the width of the edges correspond to the absolute weight and scale relative to the strongest weight in the graph, respectively. The circular layout shows how well the data conforms to the model while the force-oriented layout shows how each node (connected and unconnected) repulses the other, and how connected nodes attract each other. See also Supplementary Figures.

$\mid$ Cor $\mid>0.25$

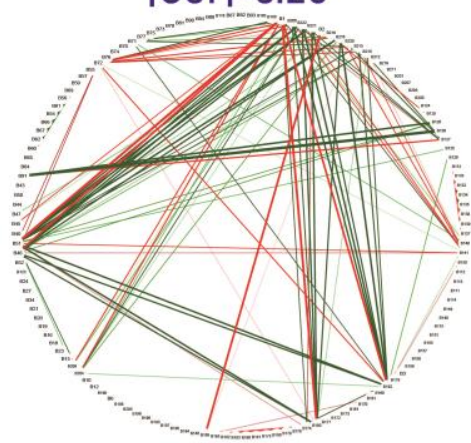

$\mid$ Cor $\mid>0.25$

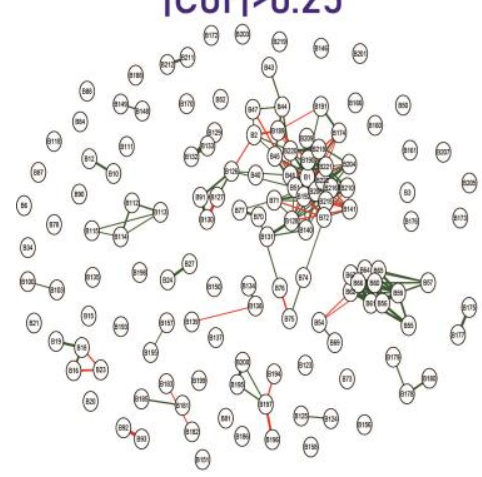

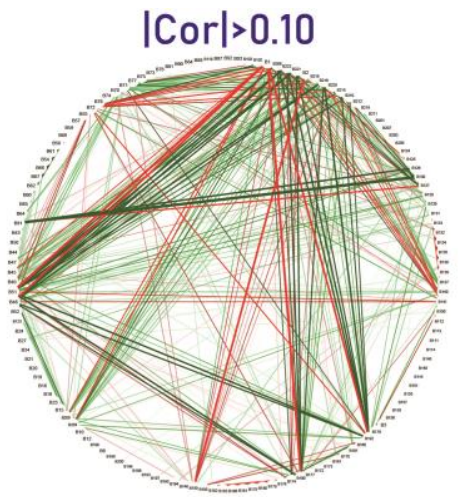

$\mid$ Cor $\mid>0.10$

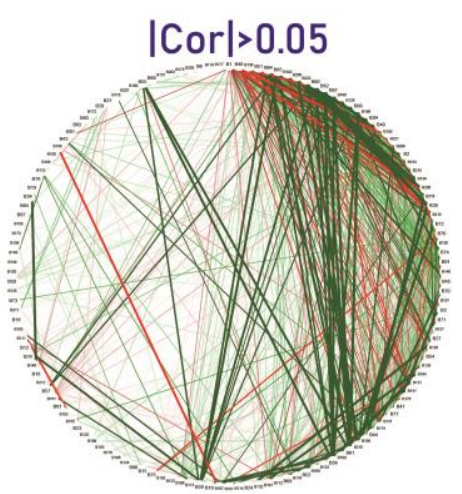

$\mid$ Cor $\mid>0.05$
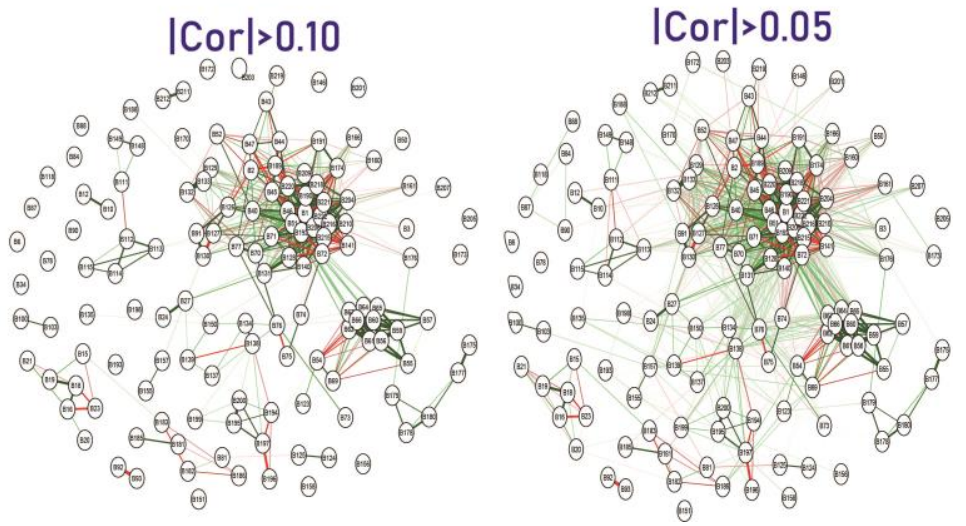
bioRxiv preprint doi: https://doi.org/10.1101/855809; this version posted November 26,2019 . The copyright holder for this preprint (which was not certified by peer review) is the author/funder, who has granted bioRxiv a license to display the preprint in perpetuity. It is made available under aCC-BY-NC-ND 4.0 International license.

Figure 4. Representative candidate markers for unhealthy physical status. A linear regression model was used to compare PEIs between healthy physical states and unhealthy physical states after adjusting for sex and age. Significantly different PEIs $(P<0.05)$ after Bonferroni adjustment $\left(P<0.05 / 34\right.$ unhealthy states $\left.=1.4 \times 10^{-3}\right)$ are shown. See also Supplementary Table 36.

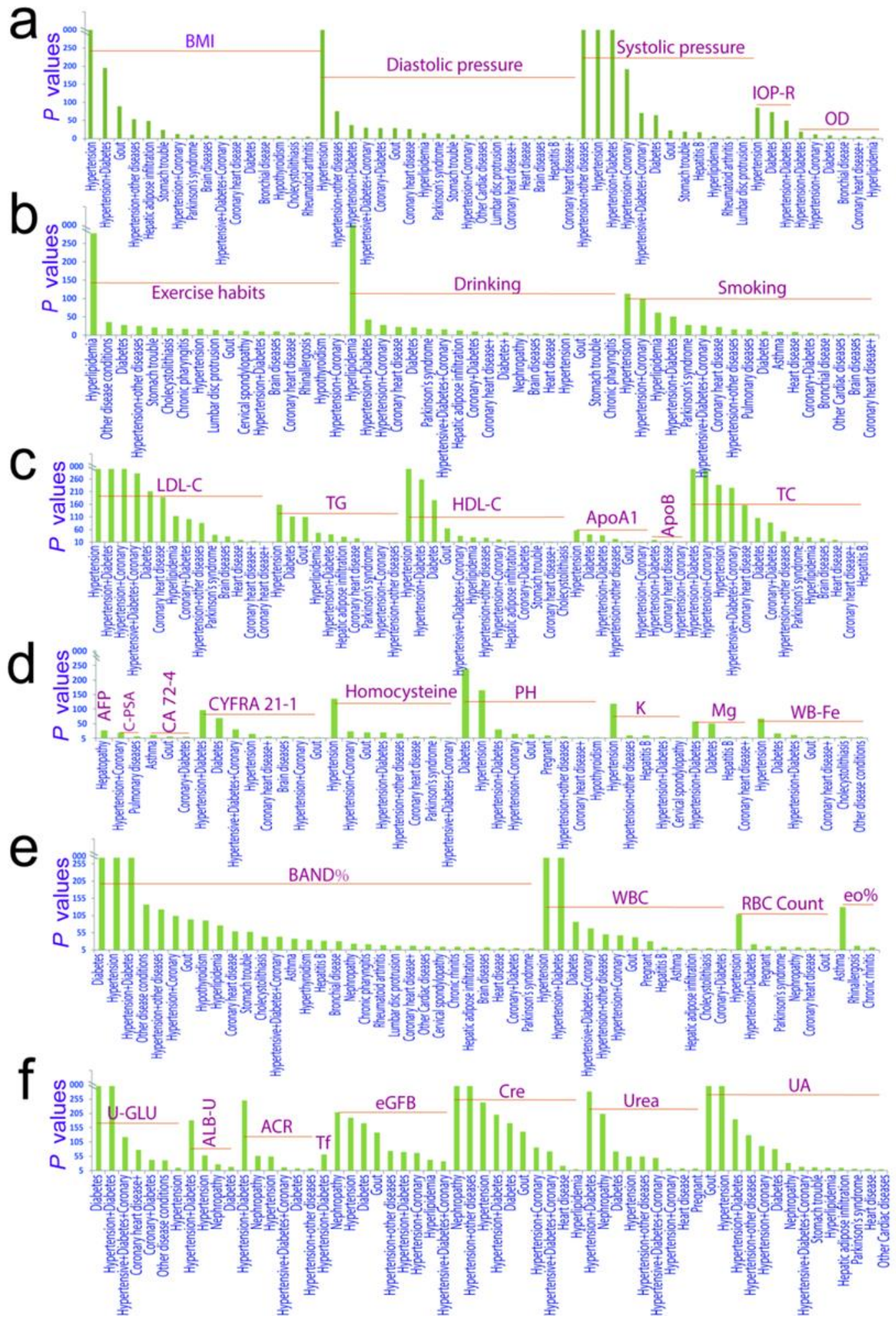


Figure 5. Machine learning prediction of the 35 physical status by the random forest algorism.

The receiver operating characteristic curve takes the false positive rate (FPR) as the horizontal axis and the true positive rate (TPR) as the vertical axis. The horizontal axis represents the proportion of the actual negative instances in the positive class predicted by the classifier to all the negative instances, while the vertical axis represents the proportion of the actual positive instances in the positive class predicted by the classifier to all the positive instances. The AUC is the area under the ROC curve.
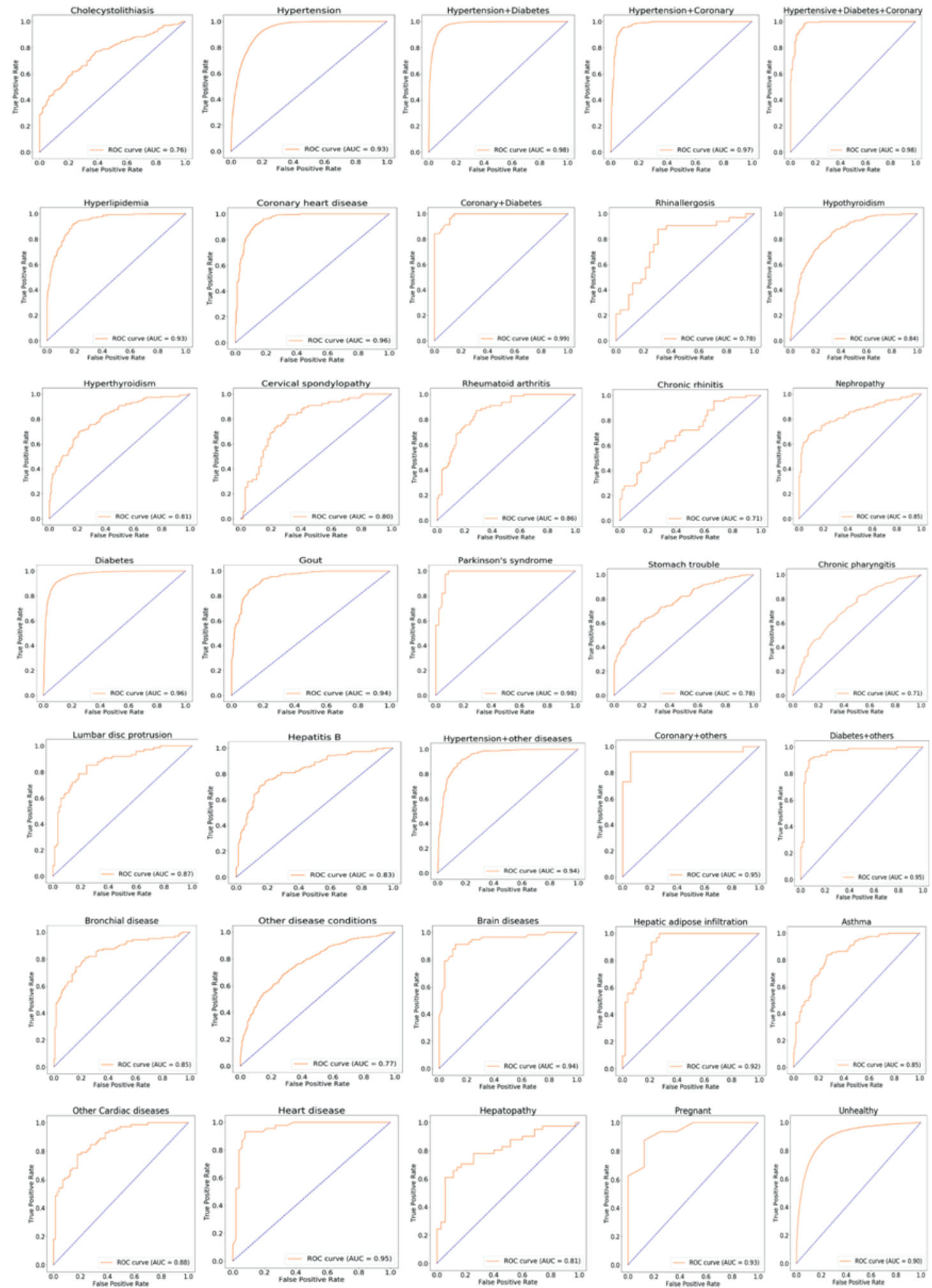
Extended data Table 1. PEIs used in this study

\begin{tabular}{|c|c|c|c|}
\hline Code & PEI Name & PEI Name abbreviation & Unit \\
\hline B1 & Gender & Gender & - \\
\hline B2 & Age & Age & years \\
\hline B3 & Homocysteine & Hcy & $\mathrm{umol} / \mathrm{L}$ \\
\hline B4 & Whole Blood Calcium & WB-Ca & $\mathrm{mmol} / \mathrm{L}$ \\
\hline B5 & Whole Blood Magnesium & WB-Mg & $\mathrm{mmol} / \mathrm{L}$ \\
\hline B6 & Iron Of Whole Blood & WB-Fe & $\mathrm{mmol} / \mathrm{L}$ \\
\hline B7 & Whole Blood Copper & WB-Cop & umol/L \\
\hline B8 & Zinc In Whole Blood & WB-Zinc & $\mathrm{umol} / \mathrm{L}$ \\
\hline B9 & Rh Blood Group & RH & - \\
\hline B10 & Pepsinogen I & PGI & $\mathrm{ug} / \mathrm{L}$ \\
\hline B11 & PgI/PgII & PGI/PGII & - \\
\hline B12 & Pepsinogen II & PGII & $\mathrm{ug} / \mathrm{L}$ \\
\hline B14 & Gastrin-17 & G-17 & $\mathrm{pmol} / \mathrm{l}$ \\
\hline B15 & Cd3-Cd19+(B Cell) & CD3-CD19+(B cell) & - \\
\hline B16 & Cd3+ Total T Lymphocyte & $\mathrm{CD} 3+\mathrm{T}$ & - \\
\hline B17 & $\mathrm{Cd} 3+\mathrm{Cd} 16+\mathrm{Cd} 56+\mathrm{Nk}$ & $\mathrm{CD} 3+\mathrm{CD} 16+\mathrm{CD} 56+\mathrm{NK}$ & - \\
\hline B18 & $\mathrm{Cd} 3+\mathrm{Cd} 4+\mathrm{Helper}($ Inducer)T Cells & $\mathrm{CD} 3+\mathrm{CD} 4+$ helper(inducer) $\mathrm{T}$ & - \\
\hline B19 & $\mathrm{Cd} 3+\mathrm{Cd} 4+/ \mathrm{Cd} 3+\mathrm{Cd} 8+$ & CD3+CD4+/CD3+CD8+ & - \\
\hline B20 & $\mathrm{Cd} 3+\mathrm{Cd} 4+\mathrm{Cd} 8+$ & $\mathrm{CD} 3+\mathrm{CD} 4+\mathrm{CD} 8+$ & - \\
\hline B21 & $\mathrm{Cd} 3+\mathrm{Cd} 4-\mathrm{Cd} 8-$ & $\mathrm{CD} 3+\mathrm{CD} 4-\mathrm{CD} 8-$ & - \\
\hline B22 & $\mathrm{Cd} 3+\mathrm{Cd} 8+(\mathrm{T})$ & $\mathrm{CD} 3+\mathrm{CD} 8+(\mathrm{T})$ & - \\
\hline B23 & $\mathrm{Cd} 3-\mathrm{Cd} 16+\mathrm{Cd} 56+(\mathrm{Nk})$ & CD3-CD16+CD56+(NK) & - \\
\hline B24 & $\alpha$ Hydroxybutyrate Dehydrogenas & $\alpha \mathrm{HBDH}$ & $\mathrm{U} / \mathrm{L}$ \\
\hline B25 & Creatine Kinase & $\mathrm{CK}$ & $\mathrm{U} / \mathrm{L}$ \\
\hline B26 & Creatine Kinase Isoenzyme & CKMB & $\mathrm{U} / \mathrm{L}$ \\
\hline B27 & Lactic Dehydrogenase & LDH & $\mathrm{U} / \mathrm{L}$ \\
\hline B28 & Pituitary Prolactin & PRL & $\mathrm{mIU} / \mathrm{L}$ \\
\hline B29 & Estradiol E2 & E2 & $\mathrm{pmol} / \mathrm{L}$ \\
\hline B30 & Luteinizing Hormone & LH & $\mathrm{mIU} / \mathrm{ml}$ \\
\hline B31 & Follicle Stimulating Hormone & FSH & $\mathrm{mIU} / \mathrm{ml}$ \\
\hline B32 & Testosterone & Testo & $\mathrm{nmol} / \mathrm{L}$ \\
\hline B33 & Progesterone & Prog & $\mathrm{nmol} / \mathrm{L}$ \\
\hline B34 & Thymidine Kinase & TK & $\mathrm{PM} / \mathrm{L}$ \\
\hline B35 & Blood Beta-Microglobulin & $\beta 2-\mathrm{MG}$ & - \\
\hline B36 & Variant Lymphocyte Rate & V-Lym\% & - \\
\hline B37 & Band Cell & BAND & $10 \mathrm{E}-9 / \mathrm{L}$ \\
\hline B38 & Band Cell\% & BAND $\%$ & - \\
\hline B39 & Other Cell Types & Other cells & - \\
\hline B40 & Leukocyte Count & WBC & $10 \mathrm{E}-9 / \mathrm{L}$ \\
\hline B41 & Monocytes & MON & - \\
\hline
\end{tabular}




\begin{tabular}{|c|c|c|c|}
\hline B42 & Monocytes \% & MON \% & 10E-9/L \\
\hline B43 & Mean Corpuscular Volume & $\mathrm{MCV}$ & $\mathrm{fl}$ \\
\hline B44 & Mean Corpuscular Hemoglobin & $\mathrm{MCH}$ & pg \\
\hline B45 & Mean Corpuscular Hemoglobin Concentration & $\mathrm{MCHC}$ & $\mathrm{g} / \mathrm{l}$ \\
\hline B46 & Red Blood Cell Count & RBC Count & $10 \mathrm{E}-12 / \mathrm{L}$ \\
\hline B47 & Red Cell Distribution Width & RDW & $\mathrm{fl}$ \\
\hline B48 & Lymphocyte Rate & LYM\% & - \\
\hline B49 & Basophilic Granulocyte Rate & baso $\%$ & - \\
\hline B50 & Eosinophil Rate & $\mathrm{eo} \%$ & - \\
\hline B51 & Hemoglobin & $\mathrm{Hb}$ & $g / L$ \\
\hline B52 & Platelet Count & $\mathrm{PLT} / \mathrm{BPC}$ & $10 \mathrm{E}-9 / \mathrm{L}$ \\
\hline B53 & Granulocyte Rate & GR\% & - \\
\hline B54 & Erythrocyte Sedimentation Rate & ESR & $\mathrm{mm} / 60 \mathrm{~min}$ \\
\hline B55 & Erythrocyte Deformation Index & TK & - \\
\hline B56 & The Index Of Rigidity Of Erythrocyte & IR & - \\
\hline B57 & Erythrocyte Aggregation Indices & RBCAI & - \\
\hline B58 & Hematocrit & HCT & - \\
\hline B59 & Whole Blood Reduced Viscosity & WBRV & - \\
\hline B60 & Whole Blood Reduced Viscosity Index & WBRVI & - \\
\hline B61 & Whole Blood High Shear Reduced Viscosity & WBHSRV & - \\
\hline B62 & Whole Blood High Shear Reduced Viscosity Index & WBHSRVI & - \\
\hline B63 & Shear Rate Of Whole Blood Viscosity_Mpas_1 (200) & WBRSR(mPas_200) & - \\
\hline B64 & Shear Rate Of Whole Blood Viscosity_Mpas_3 (5) & WBRSR(mPas_5) & - \\
\hline B65 & Shear Rate Of Whole Blood Viscosity_Mpas_4 (1) & WBRSR(mPas_1) & - \\
\hline B66 & Shear Rate Of Whole Blood Viscosity_Mpas (100) & WBRSR(mPas_100) & - \\
\hline B67 & Shear Rate Of Whole Blood Viscosity_Mpas (50) & WBRSR(mPas_50) & - \\
\hline B69 & Plasma Viscosity & PV & - \\
\hline B70 & Low-Density Lipoprotein & LDL-C & $\mathrm{mmol} / \mathrm{L}$ \\
\hline B71 & Triglyceride & TG & $\mathrm{mmol} / \mathrm{L}$ \\
\hline B72 & High-Density Lipoprotein & HDL-C & $\mathrm{mmol} / \mathrm{L}$ \\
\hline B73 & Apolipoprotein A & ApoA & $\mathrm{mg} / \mathrm{L}$ \\
\hline B74 & Apolipoprotein A1 & ApoA1 & $\mathrm{g} / \mathrm{L}$ \\
\hline B75 & Apolipoprotein A1/B & ApoA1/B & $\mathrm{g} / \mathrm{L}$ \\
\hline B76 & Apolipoprotein B & ApoB & $\mathrm{g} / \mathrm{L}$ \\
\hline B77 & Total Cholesterol & $\mathrm{TC}$ & $\mathrm{mmol} / \mathrm{L}$ \\
\hline B78 & Hepatitis B Virus Core Im Antibod & $\mathrm{HBcAb}$ & - \\
\hline B79 & Quantitative Detection Of Hepatitis B Virus Dna & hbV-dna & $\mathrm{IU} / \mathrm{ml}$ \\
\hline B80 & Helicobacter Pylori Antibody-Igg & anti-HP IgG & - \\
\hline B81 & Tumor Supplied Group Of Factors & TSGF & $\mathrm{U} / \mathrm{ML}$ \\
\hline B82 & Carcinoembryonic Antigen & CEA & $\mathrm{ng} / \mathrm{ml}$ \\
\hline B83 & Alpha-Fetoprotein & AFP & $\mathrm{ng} / \mathrm{ml}$ \\
\hline B84 & Complexed Prostate Special Antigen & C-PSA & $\mathrm{ng} / \mathrm{ml}$ \\
\hline B85 & Squamous Cell Carcinoma Antigen & SCC & $\mathrm{ng} / \mathrm{ml}$ \\
\hline B86 & Chorionic Gonadotropin & TBhCG & $\mathrm{mIU} / \mathrm{ml}$ \\
\hline
\end{tabular}




\begin{tabular}{|c|c|c|c|}
\hline B87 & Neuron-Specific Enolase & NSE & $\mathrm{ng} / \mathrm{ml}$ \\
\hline B88 & Carbohydrate Antigen, Ca242 & CA 242 & $\mathrm{U} / \mathrm{ml}$ \\
\hline B89 & Carbohydrate Antigen, Ca72_4 & CA 72-4 & $\mathrm{U} / \mathrm{ml}$ \\
\hline B90 & Cytokeratin-19-Fragment Cyfra21-1 & CYFRA 21-1 & $\mathrm{ng} / \mathrm{ml}$ \\
\hline B91 & Total Protein & TP & $\mathrm{g} / \mathrm{L}$ \\
\hline B92 & Aldh2-Glu504Glu & ALDH2-Glu504Glu & - \\
\hline B93 & Aldh2-Glu504Lys & ALDH2-Glu504Lys & - \\
\hline B94 & Aldh2-Lys504Lys & ALDH2-Lys504Lys & - \\
\hline B95 & Anti-Cenpb & anti-cenpb & - \\
\hline B96 & Dsdna (Iif) & dsDNA (IIF) & - \\
\hline B97 & Anti-Dsdna Antibody & dsDNA & - \\
\hline B98 & Jo-1 Antibody & anti-Jo-1 & - \\
\hline B99 & Anti-Pm-Scl & anti-PM-Scl & - \\
\hline B100 & Anti-Ro52 & anti-Ro52 & - \\
\hline B101 & Anti-Sc70 & anti-Sc70 & - \\
\hline B102 & Anti Sm Antibody & anti-Sm & - \\
\hline B103 & Anti-Ssa/Ro Antibody & anti-SSA/Ro & - \\
\hline B104 & Anti Ssb Antibody & anti-SSB & - \\
\hline B105 & Anti-U1Rnp Antibody & anti-U1RNP & - \\
\hline B106 & Anti-Ribosomal P Protein Antibody & anti-P & - \\
\hline B107 & Anti-Nucleosome Antibody Systemic & AnuA & - \\
\hline B108 & Anti-Cyclin Antibody & Anti-Cyclin & - \\
\hline B109 & Antimitochondrial Antibody M2 & AMA-M2 & - \\
\hline B110 & Anti-Histone Antibody & AHA & - \\
\hline B111 & Thyroid-Stimulating Hormon & TSH & $\mathrm{mIU} / \mathrm{L}$ \\
\hline B112 & Free Thyroxine & FT4 & $\mathrm{pmol} / \mathrm{L}$ \\
\hline B113 & Free Triiodothyronine & FT3 & $\mathrm{pmol} / \mathrm{L}$ \\
\hline B114 & Total Thyroxine & TSH TT3 TT4(TT4) & $\mathrm{nmol} / \mathrm{L}$ \\
\hline B115 & Total Triiodothyronine & TSH TT3 TT4(TT3) & $\mathrm{nmol} / \mathrm{L}$ \\
\hline B116 & Total Triiodothyronine & TT3 & $\mathrm{nmol} / \mathrm{L}$ \\
\hline B117 & Total Thyroxine & TT4 & $\mathrm{nmol} / \mathrm{L}$ \\
\hline B118 & Carcinoembryonic Antigen 1 & CEA1 & $\mathrm{ng} / \mathrm{ml}$ \\
\hline B119 & Quantitative Detection Of Hepatitis C Virus Rna & Hev-rna & - \\
\hline B120 & Hev Core Antigen & $\mathrm{HCV}-\mathrm{cAg}$ & - \\
\hline B121 & Complement $\mathrm{C} 3$ & $\mathrm{C} 3$ & - \\
\hline B122 & Complement $\mathrm{C} 4$ & $\mathrm{C} 4$ & - \\
\hline B123 & High Sensitivity C-Reactive Protein 1 & hs-CRP1 & $\mathrm{mg} / \mathrm{L}$ \\
\hline B124 & Adrenocorticotropic Hormone & ACTH & $\mathrm{pg} / \mathrm{ml}$ \\
\hline B125 & Cortisol & Cor & $\mathrm{ug} / \mathrm{dl}$ \\
\hline B126 & Albumin & Alb & $\mathrm{g} / \mathrm{L}$ \\
\hline B127 & Albumin-Globulin & A-G ratio & - \\
\hline B128 & Alanine Aminotransferase & ALT & $\mathrm{U} / \mathrm{L}$ \\
\hline B129 & Indirect Bilirubin & IBIL & $\mathrm{umol} / \mathrm{L}$ \\
\hline B130 & Globulin & GLB & $\mathrm{g} / \mathrm{L}$ \\
\hline
\end{tabular}




\begin{tabular}{|c|c|c|c|}
\hline B131 & Aspartate Transaminase & AST & $\mathrm{U} / \mathrm{L}$ \\
\hline B132 & Direct Bilirubin & Dbil & umol/L \\
\hline B133 & Total Bilirubin & TBIL & $\mathrm{umol} / \mathrm{L}$ \\
\hline B134 & Cholinesterases & $\mathrm{CHE}$ & $\mathrm{KU} / \mathrm{L}$ \\
\hline B135 & Total Bile Acid & TBA & umol/L \\
\hline B136 & 5-Nucleotidase & 5 'NT & $\mathrm{U} / \mathrm{L}$ \\
\hline B137 & Alpha-L-Fucosidase & AFU & $\mathrm{U} / \mathrm{L}$ \\
\hline B138 & Prealbumin & $\mathrm{PAB}$ & $\mathrm{mg} / \mathrm{L}$ \\
\hline B139 & Adenosine Deaminase & $\mathrm{ADA}$ & $\mathrm{U} / \mathrm{L}$ \\
\hline B140 & R-Glutamyl Transpeptidase & r-GT & $\mathrm{U} / \mathrm{L}$ \\
\hline B141 & Ast/Alt & AST/ALT & - \\
\hline B142 & 25-Hydroxyvitamin D & $25-(\mathrm{OH}) \mathrm{D}$ & $\mathrm{ng} / \mathrm{mL}$ \\
\hline B143 & $\beta$-Crosslaps & $\beta-\mathrm{CTx}$ & $\mathrm{pg} / \mathrm{mL}$ \\
\hline B144 & Total-Pinp & Total-PINP & $\mathrm{ng} / \mathrm{mL}$ \\
\hline B145 & Osteocalcin & BGP & $\mathrm{ng} / \mathrm{mL}$ \\
\hline B146 & Cystatin C & CysC & $\mathrm{mg} / \mathrm{L}$ \\
\hline B148 & Antithyroperoxidase Antibody & Anti_TPO & $\mathrm{IU} / \mathrm{ml}$ \\
\hline B149 & Anti-Thyroglobulin Antibodies & TGAb & $\mathrm{IU} / \mathrm{ml}$ \\
\hline B150 & Alkaline Phosphatase & ALP & $\mathrm{U} / \mathrm{L}$ \\
\hline B151 & Anti-Cyclic Peptide Containing Citrulline & Anti-CCP & $\mathrm{Ru} / \mathrm{ml}$ \\
\hline B152 & Anti Cardiolipin Antibodyig(G-A-M) & ACA- $\operatorname{Ig}(\mathrm{G}-\mathrm{A}-\mathrm{M})$ & $\mathrm{u} / \mathrm{ml}$ \\
\hline B153 & Glucose & Glu & $\mathrm{mmol} / \mathrm{L}$ \\
\hline B154 & Rheumatoid Factor & $\mathrm{RF}$ & $\mathrm{IU} / \mathrm{ml}$ \\
\hline B155 & Immunoglobulin A & $\operatorname{Ig} A$ & $\mathrm{~g} / \mathrm{l}$ \\
\hline B156 & Immunoglobulin E & $\operatorname{IgE}$ & $\mathrm{IU} / \mathrm{ml}$ \\
\hline B157 & Immunoglobulin G & $\mathrm{IgG}$ & $\mathrm{g} / 1$ \\
\hline B158 & Immunoglobulin $\mathrm{M}$ & $\operatorname{IgM}$ & $\mathrm{g} / \mathrm{l}$ \\
\hline B159 & Urine Beta-Microglobulin & $\beta 2-\mathrm{MG}$ & - \\
\hline B160 & $\mathrm{Ph}$ & $\mathrm{PH}$ & - \\
\hline B161 & Leucocyte & LEU & $/ \mathrm{ul}$ \\
\hline B163 & Specific Gravity & SG & - \\
\hline B164 & Calcium Oxalate Crystals & $\mathrm{COM}$ & HPF \\
\hline B165 & Bilirubin & bilirubin & - \\
\hline B166 & Protein & Pro & - \\
\hline B167 & Phosphate Crystals & $\mathrm{PC}$ & - \\
\hline B168 & Urinary Nuclear Matrix Protein 22 & NMP22 & - \\
\hline В169 & Urate Crystal & U-CRY & - \\
\hline B170 & Urine Sugar & U-GLU & - \\
\hline B171 & Epithelial Cell & $\mathrm{EC}$ & HPF \\
\hline B172 & Ketone Body & $\mathrm{KB}$ & - \\
\hline B173 & Nitrous Acid & NTT & - \\
\hline B174 & Urea Creatinine & $\mathrm{Urea} / \mathrm{Cr}$ & - \\
\hline B175 & Microalbuminuria & ALB-U & $\mathrm{mg} / \mathrm{L}$ \\
\hline B176 & Urine Creatinine & Ucr & umol/L \\
\hline
\end{tabular}




\begin{tabular}{|c|c|c|c|}
\hline B177 & Ratio Of Urinary Microalbumin To Creatinin & ACR & $\mathrm{ug} / \mathrm{mg}$ \\
\hline B178 & Urinary Immunoglobulin G & Ig-U & $\mathrm{mg} / \mathrm{L}$ \\
\hline B179 & Urine Alpha-Microglobulin & $\alpha 1-\mathrm{MG}$ & $\mathrm{mg} / \mathrm{L}$ \\
\hline B180 & Urine Transferrin & $\mathrm{Tf}$ & $\mathrm{mg} / \mathrm{L}$ \\
\hline B181 & Activated Partial Thromboplastin Time & APTT & $\mathrm{s}$ \\
\hline B182 & Thrombin Time & TT & $\mathrm{s}$ \\
\hline B183 & Percentage Activity Of Prothrombin In Plasma & PTA & - \\
\hline B184 & International Normalized Ratio & INR & - \\
\hline B185 & Prothrombin Time & PT & $\mathrm{s}$ \\
\hline B186 & Plasma Fibrinogen Concentration & $\mathrm{PFC}$ & $\mathrm{g} / \mathrm{l}$ \\
\hline B187 & Neuron-Specific Enolase & NSE & $\mathrm{ng} / \mathrm{ml}$ \\
\hline B188 & Calcium & $\mathrm{Ca}$ & $\mathrm{mmol} / \mathrm{L}$ \\
\hline B189 & Estimated Glomerular Filtration Rate & eGFB & $\mathrm{ml} / \mathrm{min}$ \\
\hline B190 & Creatinine & Cre & $\mathrm{umol} / \mathrm{L}$ \\
\hline B191 & Urea & Urea & $\mathrm{mmol} / \mathrm{L}$ \\
\hline B192 & Uric Acid & UA & $\mathrm{umol} / \mathrm{L}$ \\
\hline B193 & Kalium & $\mathrm{K}$ & $\mathrm{mmol} / \mathrm{L}$ \\
\hline B194 & Chlorine & $\mathrm{Cl}$ & $\mathrm{mmol} / \mathrm{L}$ \\
\hline B195 & Sodium & $\mathrm{Na}$ & $\mathrm{mmol} / \mathrm{L}$ \\
\hline B196 & Blood Carbon Dioxide & $\mathrm{TCO} 2$ & $\mathrm{mmol} / \mathrm{L}$ \\
\hline B197 & Anion Gap & AG & $\mathrm{mmol} / \mathrm{L}$ \\
\hline B198 & Phosphorus & $\mathrm{P}$ & $\mathrm{mmol} / \mathrm{L}$ \\
\hline В199 & Magnesium & $\mathrm{Mg}$ & $\mathrm{mmol} / \mathrm{L}$ \\
\hline B200 & Osmotic Pressure & OP & $\mathrm{mOsm} / \mathrm{L}$ \\
\hline B201 & Exercise Habits & e-habits & - \\
\hline В202 & Frequency Of Exercises & e-times & - \\
\hline B203 & Dietary Habits 1 & DH & - \\
\hline B204 & History Of Alcohol Intake & Drinking & - \\
\hline В205 & Known Of Drug Allergy & KDA & - \\
\hline B206 & Waistline & Waist & $\mathrm{cm}$ \\
\hline B207 & Waist-Hip Ratio & WHR & - \\
\hline В209 & Smoking History & Smoking & - \\
\hline B210 & Hipline & Hip & $\mathrm{cm}$ \\
\hline B211 & Intra-Ocular Tension Of The Right Eye & IOP-R & $\mathrm{mmHg}$ \\
\hline B212 & Intra-Ocular Tension Of The Left Eye & IOP-L & $\mathrm{mmHg}$ \\
\hline B213 & Corrected Visual Acuity The Right Eye & CVA-R & - \\
\hline B214 & Corrected Visual Acuity The Left Eye & CVA-L & - \\
\hline B215 & Body Mass Index & BMI & - \\
\hline B216 & Body Mass & BMI & $\mathrm{kg}$ \\
\hline B218 & Diastolic Pressure & DBP & $\mathrm{mmHg}$ \\
\hline B219 & Operation History & OT & - \\
\hline B220 & Systolic Pressure & SBP & $\mathrm{mmHg}$ \\
\hline B221 & Height & Hei & $\mathrm{cm}$ \\
\hline B222 & Neck Size & NS & $\mathrm{cm}$ \\
\hline
\end{tabular}


bioRxiv preprint doi: https://doi.org/10.1101/855809; this version posted November 26, 2019. The copyright holder for this preprint (which was not certified by peer review) is the author/funder, who has granted bioRxiv a license to display the preprint in perpetuity. It is made available under aCC-BY-NC-ND 4.0 International license.

\begin{tabular}{llll} 
B223 & Family History & FH & - \\
B224 & Anamnesis & pmh & - \\
B225 & Hourly Postprandial Blood Sugar & hPBG & $\mathrm{mmol} / \mathrm{L}$ \\
B227 & Vision Of The Right Eye & OD & - \\
B228 & Vision Of The Left Eye & OS & - \\
\hline
\end{tabular}


Extended data Table 2. List of the $15 \%$ or $16 \%$ representative PEIs were extracted for machine learning prediction by feature extraction.

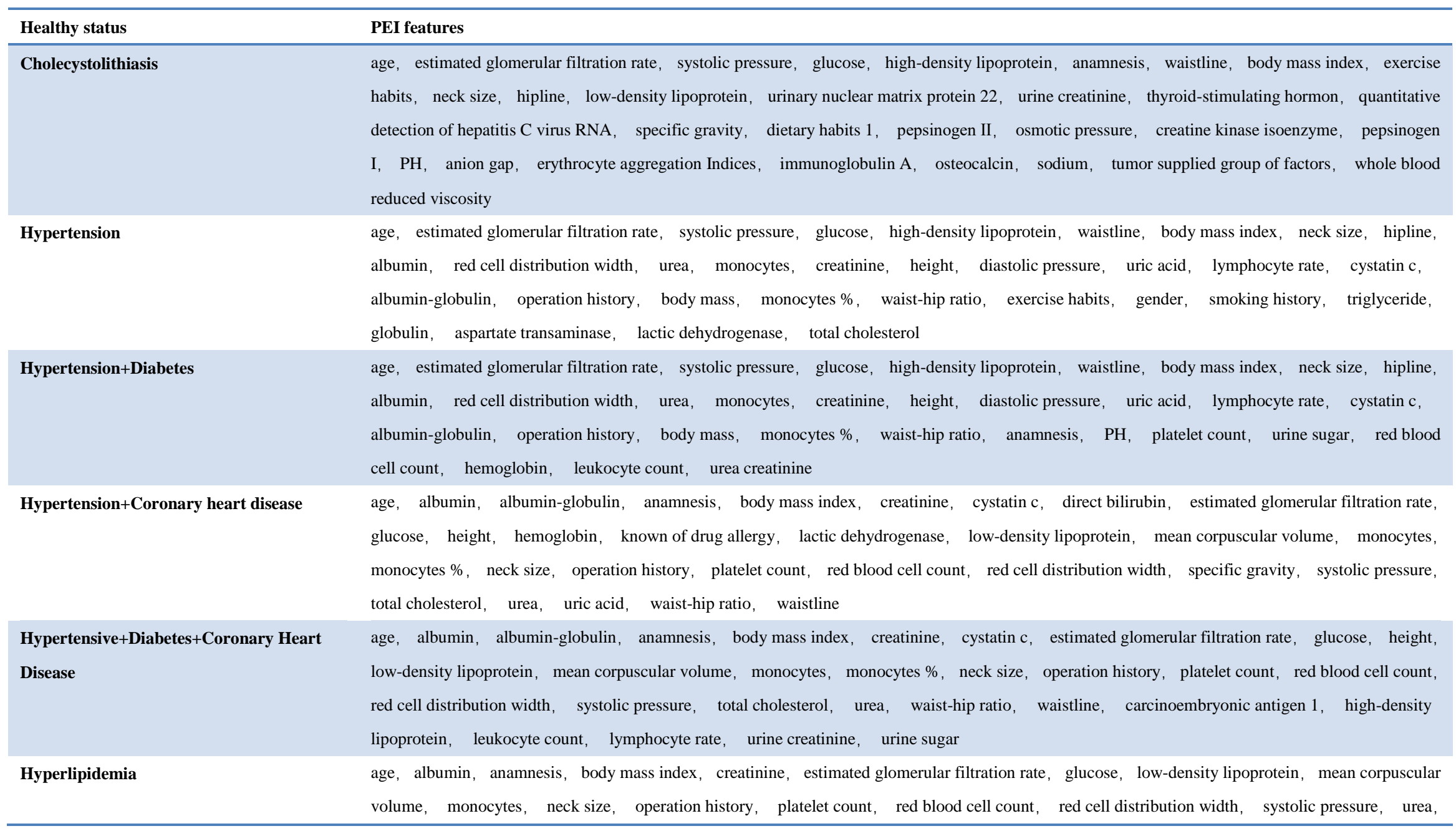


waist-hip ratio, waistline, carcinoembryonic antigen 1, high-density lipoprotein, urine creatinine, known of drug allergy, specific gravity, uric acid, exercise habits, gender, history of alcohol intake, mean corpuscular hemoglobin, smoking history, total Protein, triglyceride

Coronary heart disease

Coronary heart disease+Diabetes

Rhinallergosis

Cervical spondylopathy age, albumin, anamnesis, body mass index, creatinine, estimated glomerular filtration rate, glucose, low-density lipoprotein, mean corpuscular volume, monocytes, neck size, operation history, platelet count, red blood cell count, red cell distribution width, systolic pressure, urea, waist-hip ratio, waistline, carcinoembryonic antigen 1, known of drug allergy, gender, mean corpuscular hemoglobin, total Protein, cystatin c, monocytes \%, total cholesterol, direct bilirubin, lactic dehydrogenase, calcium, dietary habits 1, eosinophil rate age, albumin, anamnesis, body mass index, creatinine, estimated glomerular filtration rate, glucose, low-density lipoprotein, mean corpuscular volume, monocytes, neck size, operation history, platelet count, red blood cell count, red cell distribution width, systolic pressure, urea waist-hip ratio, waistline, carcinoembryonic antigen 1, gender, mean corpuscular hemoglobin, monocytes \%, total cholesterol, urine sugar, adenosine deaminase, alpha-l-fucosidase, CD3+CD16+CD56+NK, pepsinogen I, PH

albumin, anamnesis, mean corpuscular volume, platelet count, waist-hip ratio, mean corpuscular hemoglobin, CD3+CD16+CD56+NK, known of drug allergy, total Protein, dietary habits 1, eosinophil rate, uric acid, exercise habits, triglyceride, 5-nucleotidase, alkaline phosphatase AST/ALT, blood carbon dioxide, carcinoembryonic antigen, cholinesterases, erythrocyte sedimentation rate, free triiodothyronine, hematocrit, immunoglobulin M, Indirect bilirubin, total bilirubin, urinary nuclear matrix protein 22, vision of the left eye, vision of the right eye, whole blood high shear reduced viscosity index

albumin, anamnesis, uric acid, AST/ALT, free triiodothyronine, age, creatinine, monocytes, neck size, red blood cell count, red cel distribution width, waistline, gender, monocytes \%, high-density lipoprotein, specific gravity, history of alcohol intake, smoking history, albumin-globulin, height, leukocyte count, hemoglobin, alanine aminotransferase, anti-thyroglobulin antibodies, antithyroperoxidase antibody, body mass, diastolic pressure, mean corpuscular hemoglobin concentration, protein, r-glutamyl transpeptidase, thyroid-stimulating hormon, total Triiodothyronine, urea creatinine

albumin, anamnesis, age, creatinine, neck size, gender, high-density lipoprotein, specific gravity, history of alcohol intake, height, hemoglobin, anti-thyroglobulin antibodies, antithyroperoxidase antibody, body mass, protein, r-glutamyl transpeptidase, urea creatinine, mean corpuscular volume, dietary habits 1 , triglyceride, immunoglobulin M, Indirect bilirubin, body mass index, operation history, carcinoembryonic antigen 1, urine creatinine, free thyroxine, hipline, PGI/PGII, plasma fibrinogen concentration, total thyroxine, urine transferri albumin, anamnesis, age, high-density lipoprotein, specific gravity, height, body mass, operation history, urine creatinine, hipline, plasma fibrinogen concentration, alanine aminotransferase, known of drug allergy, exercise habits, 5-nucleotidase, erythrocyte sedimentation rate, 
estimated glomerular filtration rate, glucose, systolic pressure, urea, urine sugar, alpha-fetoprotein, anti-cyclic peptide containing citrulline, apolipoprotein A, CD3+ Total T lymphocyte, corrected visual acuity the left eye, gastrin-17, hourly postprandial blood sugar, intra-ocular tension of the left eye, kalium, magnesium, neuron-specific enolase

\begin{tabular}{|c|c|}
\hline Rheumatoid arthritis & $\begin{array}{l}\text { albumin, anamnesis, age, high-density lipoprotein, specific gravity, height, body mass, hipline, known of drug allergy, estimated glomerular } \\
\text { filtration rate, systolic pressure, gastrin-17, neck size, gender, history of alcohol intake, hemoglobin, protein, urea creatinine, body mass } \\
\text { index, uric acid, monocytes, red blood cell count, red cell distribution width, albumin-globulin, mean corpuscular hemoglobin concentration, } \\
\text { vision of the left eye, vision of the right eye, lactic dehydrogenase, lymphocyte rate, globulin, leucocyte, a hydroxybutyrate dehydrogenas }\end{array}$ \\
\hline Chronic rhinitis & $\begin{array}{l}\text { albumin, anamnesis, age, high-density lipoprotein, height, estimated glomerular filtration rate, systolic pressure, gender, hemoglobin, } \\
\text { protein, urea creatinine, uric acid, albumin-globulin, mean corpuscular hemoglobin concentration, lactic dehydrogenase, 5-nucleotidase, } \\
\text { creatinine, dietary habits 1, triglyceride, total thyroxine, free triiodothyronine, diastolic pressure, eosinophil rate, alkaline phosphatase, total } \\
\text { cholesterol, apolipoprotein B, erythrocyte aggregation Indices, granulocyte rate, helicobacter pylori antibody-IgG, hepatitis B virus core IM } \\
\text { antibod, quantitative detection of hepatitis B virus DNA }\end{array}$ \\
\hline Nephropathy & $\begin{array}{l}\text { albumin, anamnesis, age, estimated glomerular filtration rate, systolic pressure, hemoglobin, protein, urea creatinine, uric acid, } \\
\text { albumin-globulin, lactic dehydrogenase, creatinine, eosinophil rate, known of drug allergy, monocytes, red blood cell count, red cell distribution } \\
\text { width, lymphocyte rate, operation history, erythrocyte sedimentation rate, urea, Indirect bilirubin, waistline, monocytes \%, leukocyte count, } \\
\text { total Protein, pepsinogen I, cystatin c, calcium, adrenocorticotropic hormone, ALDH2-Glu504Lys, creatine kinase, pepsinogen II }\end{array}$ \\
\hline Diabetes & $\begin{array}{l}\text { albumin, anamnesis, age, estimated glomerular filtration rate, systolic pressure, urea creatinine, red cell distribution width, lymphocyte rate, } \\
\text { operation history, urea, waistline, monocytes } \% \text {, leukocyte count, high-density lipoprotein, gender, triglyceride, free triiodothyronine, } \\
\text { diastolic pressure, body mass, neck size, body mass index, exercise habits, glucose, urine sugar, AST/ALT, smoking history, platelet } \\
\text { count, waist-hip ratio, PH, cytokeratin-19-fragment CYFRA21-1, ketone body, osmotic pressure }\end{array}$ \\
\hline Gout & $\begin{array}{l}\text { anamnesis, age, estimated glomerular filtration rate, systolic pressure, urea creatinine, lymphocyte rate, waistline, monocytes \%, leukocyte } \\
\text { count, high-density lipoprotein, gender, triglyceride, diastolic pressure, body mass, neck size, body mass index, exercise habits, glucose, } \\
\text { AST/ALT, smoking history, waist-hip ratio, PH, hemoglobin, uric acid, creatinine, red blood cell count, cystatin c, height, hipline, } \\
\text { history of alcohol intake, alanine aminotransferase, r-glutamyl transpeptidase, aspartate transaminase }\end{array}$ \\
\hline Parkinson's syndrome & $\begin{array}{l}\text { anamnesis, age, estimated glomerular filtration rate, systolic pressure, lymphocyte rate, waistline, monocytes \%, leukocyte count, gender, } \\
\text { glucose, AST/ALT, waist-hip ratio, hemoglobin, creatinine, red blood cell count, history of alcohol intake, albumin, red cell distribution }\end{array}$ \\
\hline
\end{tabular}


width, urea, platelet count, monocytes, total Protein, calcium, mean corpuscular hemoglobin concentration, total cholesterol, granulocyte rate, urine creatinine, urine transferrin, low-density lipoprotein, anti-Sc70, anti-U1RNP antibody, CD3+CD4+CD8+

\begin{tabular}{|c|c|}
\hline Stomach trouble & $\begin{array}{l}\text { anamnesis, age, estimated glomerular filtration rate, monocytes } \% \text {, leukocyte count, waist-hip ratio, red blood cell count, red cell distribution } \\
\text { width, platelet count, total cholesterol, urine creatinine, low-density lipoprotein, high-density lipoprotein, body mass, body mass index, } \\
\text { exercise habits, uric acid, height, hipline, operation history, protein, known of drug allergy, specific gravity, anti Sm antibody, anti-cenpb, } \\
\text { anti-cyclin antibody, anti-dsDNA antibody, anti-histone antibody, antimitochondrial antibody M2, anti-nucleosome antibody Systemic, } \\
\text { anti-ribosomal p protein antibody, nitrous acid, rheumatoid factor }\end{array}$ \\
\hline Chronic pharyngitis & $\begin{array}{l}\text { anamnesis, red blood cell count, body mass, exercise habits, height, anti Sm antibody, anti-dsDNA antibody, anti-nucleosome antibody } \\
\text { Systemic, anti-ribosomal p protein antibody, waistline, gender, hemoglobin, creatinine, history of alcohol intake, albumin, mean corpuscular } \\
\text { hemoglobin concentration, urine transferrin, urea creatinine, neck size, albumin-globulin, dietary habits } 1, \text { globulin, leucocyte, whole blood } \\
\text { high shear reduced viscosity index, bilirubin, CD3-CD19+(B cell), percentage activity of prothrombin in plasma, shear rate of whole blood } \\
\text { viscosity_mPas (100), shear rate of whole blood viscosity_mPas (50), shear rate of whole blood viscosity_mPas_1 (200), the Index of Rigidity of } \\
\text { Erythrocyte, total bile acid, whole blood high shear reduced viscosity }\end{array}$ \\
\hline Lumbar disc protrusion & $\begin{array}{l}\text { anamnesis, body mass, exercise habits, waistline, gender, creatinine, albumin, neck size, age, estimated glomerular filtration rate, waist-hip } \\
\text { ratio, red cell distribution width, platelet count, total cholesterol, urine creatinine, low-density lipoprotein, body mass index, hipline, operation } \\
\text { history, known of drug allergy, glucose, urea, total Protein, smoking history, eosinophil rate, mean corpuscular volume, carcinoembryonic } \\
\text { antigen 1, free thyroxine, anion gap, basophilic granulocyte rate, homocysteine, ratio of urinary microalbumin to creatinin }\end{array}$ \\
\hline Hepatitis B & $\begin{array}{l}\text { anamnesis, body mass, waistline, gender, creatinine, neck size, age, estimated glomerular filtration rate, waist-hip ratio, platelet count, } \\
\text { total cholesterol, body mass index, hipline, smoking history, eosinophil rate, basophilic granulocyte rate, ratio of urinary microalbumin to } \\
\text { creatinin, height, hemoglobin, leukocyte count, AST/ALT, monocytes, calcium, granulocyte rate, cystatin c, alanine aminotransferase, } \\
\text { aspartate transaminase, vision of the right eye, kalium, adenosine deaminase, direct bilirubin, microalbuminuria, prealbumin }\end{array}$ \\
\hline Hypertension+other diseases & $\begin{array}{l}\text { anamnesis, body mass, waistline, creatinine, neck size, age, estimated glomerular filtration rate, waist-hip ratio, body mass index, hipline, } \\
\text { eosinophil rate, height, cystatin c, aspartate transaminase, exercise habits, albumin, red cell distribution width, operation history, known } \\
\text { of drug allergy, glucose, urea, mean corpuscular volume, red blood cell count, albumin-globulin, globulin, monocytes \%, uric acid, specific } \\
\text { gravity, systolic pressure, triglyceride, diastolic pressure, lactic dehydrogenase }\end{array}$ \\
\hline Coronary heart disease+other diseases & anamnesis, body mass, age, estimated glomerular filtration rate, waist-hip ratio, hipline, cystatin c, albumin, red cell distribution width, \\
\hline
\end{tabular}


operation history, urea, red blood cell count, specific gravity, systolic pressure, platelet count, total cholesterol, hemoglobin, AST/ALT monocytes, calcium, alanine aminotransferase, vision of the right eye, urine creatinine, low-density lipoprotein, total Protein, carcinoembryonic antigen 1, history of alcohol intake, protein, apolipoprotein B, vision of the left eye, apolipoprotein A, apolipoprotein a1/b

\begin{tabular}{|c|c|}
\hline Diabetes+other diseases & $\begin{array}{l}\text { anamnesis, age, estimated glomerular filtration rate, cystatin c, albumin, red cell distribution width, operation history, urea, systolic pressure, } \\
\text { platelet count, urine creatinine, carcinoembryonic antigen 1, vision of the left eye, waistline, neck size, body mass index, known of drug allergy, } \\
\text { glucose, mean corpuscular volume, gender, smoking history, dietary habits 1, high-density lipoprotein, lymphocyte rate, PH, urine sugar, } \\
\text { cytokeratin-19-fragment CYFRA21-1, mean corpuscular hemoglobin, complexed prostate special antigen, follicle stimulating hormone, luteinizing } \\
\text { hormone, pituitary prolactin }\end{array}$ \\
\hline Bronchial disease & $\begin{array}{l}\text { anamnesis, age, estimated glomerular filtration rate, albumin, red cell distribution width, operation history, urea, systolic pressure, urine } \\
\text { creatinine, waistline, neck size, known of drug allergy, mean corpuscular volume, gender, lymphocyte rate, mean corpuscular hemoglobin, } \\
\text { AST/ALT, apolipoprotein A, creatinine, eosinophil rate, height, exercise habits, albumin-globulin, globulin, monocytes \%, lactic } \\
\text { dehydrogenase, adenosine deaminase, bilirubin, ketone body, intra-ocular tension of the right eye }\end{array}$ \\
\hline Other disease conditions & $\begin{array}{l}\text { anamnesis, age, estimated glomerular filtration rate, albumin, red cell distribution width, operation history, urea, systolic pressure, waistline, } \\
\text { neck size, known of drug allergy, mean corpuscular volume, exercise habits, albumin-globulin, platelet count, body mass index, glucose, } \\
\text { urine sugar, red blood cell count, specific gravity, total cholesterol, hemoglobin, monocytes, calcium, total Protein, diastolic pressure, } \\
\text { mean corpuscular hemoglobin concentration, Indirect bilirubin, pepsinogen } I, \text { pepsinogen II, total bilirubin, alpha-l-fucosidas }\end{array}$ \\
\hline Brain diseases & $\begin{array}{l}\text { anamnesis, age, estimated glomerular filtration rate, albumin, red cell distribution width, operation history, urea, systolic pressure, waistline, } \\
\text { exercise habits, albumin-globulin, red blood cell count, hemoglobin, monocytes, calcium, total Protein, lymphocyte rate, AST/ALT, } \\
\text { creatinine, monocytes } \% \text {, lactic dehydrogenase, carcinoembryonic antigen 1, cytokeratin-19-fragment CYFRA21-1, follicle stimulating hormone, } \\
\text { waist-hip ratio, vision of the right eye, whole blood high shear reduced viscosity index, adrenocorticotropic hormone, creatine kinase isoenzyme, } \\
\text { epithelial cell, other cell types, progesterone }\end{array}$ \\
\hline Hepatic adipose infiltration & $\begin{array}{l}\text { anamnesis, albumin, systolic pressure, waistline, red blood cell count, hemoglobin, AST/ALT, creatinine, monocytes \%, waist-hip ratio, } \\
\text { neck size, mean corpuscular volume, body mass index, diastolic pressure, mean corpuscular hemoglobin concentration, alpha-l-fucosidase, } \\
\text { gender, mean corpuscular hemoglobin, height, dietary habits } 1 \text {, high-density lipoprotein, body mass, hipline, alanine aminotransferase, } \\
\text { low-density lipoprotein, history of alcohol intake, aspartate transaminase, uric acid, triglyceride, leukocyte count, r-glutamyl transpeptidase, } \\
\text { testosterone }\end{array}$ \\
\hline
\end{tabular}



concentration, gender, height, high-density lipoprotein, body mass, alanine aminotransferase, low-density lipoprotein, r-glutamyl transpeptidase, age, estimated glomerular filtration rate, red cell distribution width, albumin-globulin, total Protein, carcinoembryonic antigen 1, known of drug allergy, platelet count, specific gravity, total cholesterol, eosinophil rate, smoking history, basophilic granulocyte rate, PGI/PGII,

$\mathrm{CD} 3+\mathrm{CD} 16+\mathrm{CD} 56+\mathrm{NK}, \quad$ urinary nuclear matrix protein 22

$\begin{array}{ll}\text { Other Cardiac diseases } & \text { anamnesis, albumin, systolic pressure, waistline, red blood cell count, hemoglobin, waist-hip ratio, mean corpuscular hemoglobin concentration, } \\ & \text { gender, height, age, estimated glomerular filtration rate, red cell distribution width, albumin-globulin, known of drug allergy, platelet count, } \\ & \text { specific gravity, dietary habits 1, operation history, urea, monocytes, glucose, pepsinogen II, vision of the left eye, luteinizing hormone, } \\ & \text { direct bilirubin, urea creatinine, osmotic pressure, a hydroxybutyrate dehydrogenas, alpha-fetoprotein, magnesium, carbohydrate antigen, } \\ & \text { CA242 }\end{array}$

\section{Heart disease}

\section{Hepatopathy}

anamnesis, albumin, systolic pressure, waistline, red blood cell count, hemoglobin, waist-hip ratio, age, estimated glomerular filtration rate, red cell distribution width, albumin-globulin, platelet count, operation history, urea, monocytes, luteinizing hormone, carcinoembryonic antigen 1, creatinine, mean corpuscular volume, mean corpuscular hemoglobin, aspartate transaminase, lactic dehydrogenase,

cytokeratin-19-fragment CYFRA21-1, progesterone, urine creatinine, anti-cenpb, antimitochondrial antibody M2, CD3+CD4+CD8+, anti-cyclic peptide containing citrulline, thyroid-stimulating hormon, prothrombin time, quantitative detection of hepatitis C virus RNA

anamnesis, albumin, waistline, red blood cell count, waist-hip ratio, age, estimated glomerular filtration rate, red cell distribution width, albumin-globulin, operation history, mean corpuscular volume, mean corpuscular hemoglobin, aspartate transaminase, anti-cenpb, direct bilirubin, basophilic granulocyte rate, urinary nuclear matrix protein 22, body mass index, exercise habits, other cell types, apolipoprotein a1/b, anti Sm antibody, anti-nucleosome antibody Systemic, anti-ribosomal p protein antibody, erythrocyte sedimentation rate, corrected visual acuity the left eye, anti-PM-Scl, corrected visual acuity the right eye, high sensitivity C-reactive protein 1

albumin, red blood cell count, age, estimated glomerular filtration rate, red cell distribution width, basophilic granulocyte rate, systolic pressure, hemoglobin, urea, monocytes, creatinine, gender, height, glucose, high-density lipoprotein, low-density lipoprotein, total Protein, smoking history, diastolic pressure, history of alcohol intake, uric acid, leukocyte count, lymphocyte rate, Indirect bilirubin, total bilirubin, cystatin c, protein, granulocyte rate, leucocyte, rheumatoid factor, quantitative detection of hepatitis B virus DNA , CD3+ Total T lymphocyte, anti cardiolipin antibody $\operatorname{Ig}(\mathrm{G}-\mathrm{A}-\mathrm{M})$

Helathy or combined disease $s$ albumin, age, estimated glomerular filtration rate, red cell distribution width, systolic pressure, urea, monocytes, creatinine, gender, height, 


\begin{tabular}{ll}
\hline & glucose, high-density lipoprotein, smoking history, diastolic pressure, uric acid, lymphocyte rate, cystatin c, anamnesis, waistline, \\
& albumin-globulin, operation history, body mass index, exercise habits, platelet count, known of drug allergy, neck size, body mass, \\
& monocytes $\%$, hipline, triglyceride, urine sugar, globulin
\end{tabular}


Extended data Table 3. Predictive Validity of Models. The number of training set and valid set samples was obtained after undersampling and data random splitting. Normal condition or disease was used to classify all kinds of diseases into disease states, undersampling with samples of healthy people, and then data division. Abbreviation: receiver operating characteristic, ROC; AUC, area under the curve.

\begin{tabular}{|c|c|c|c|c|c|c|c|}
\hline & $\begin{array}{c}\text { Training set (sample } \\
\text { size) }\end{array}$ & Validation set (sample size) & F1-score $(95 \% \mathrm{CI})$ & Accuracy $(95 \%$ CI) & Specificity $(95 \% \mathrm{CI})$ & Recall (sensitivity)(95\% CI) & ROC(AUC) $(95 \%$ CI $)$ \\
\hline Cholecystolithiasis & 963 & 413 & $0.69(0.66-0.71)$ & $0.69(0.68-0.71)$ & $0.73(0.70-0.76)$ & $0.70(0.67-0.72)$ & $0.77(0.75-0.79)$ \\
\hline Hypertension & 46171 & 17987 & $0.86(0.86-0.86)$ & $0.85(0.85-0.86)$ & $0.82(0.82-0.82)$ & $0.85(0.85-0.86)$ & $0.92(0.92-0.93)$ \\
\hline Hypertension+Diabetes & 8414 & 3065 & $0.92(0.92-0.92)$ & $0.92(0.92-0.92)$ & $0.90(0.90-0.90)$ & $0.92(0.92-0.92)$ & $0.97(0.97-0.98)$ \\
\hline Hypertension+Coronary heart disease & 2032 & 871 & $0.93(0.92-0.93)$ & $0.93(0.92-0.93)$ & $0.90(0.90-0.91)$ & $0.93(0.92-0.93)$ & $0.97(0.97-0.98)$ \\
\hline Hypertensive+Diabetes+Coronary Heart Disease & 909 & 389 & $0.96(0.95-0.96)$ & $0.95(0.94-0.97)$ & $0.95(0.94-0.95)$ & $0.95(0.94-0.97)$ & $0.99(0.98-0.99)$ \\
\hline Hyperlipidemia & 1687 & 722 & $0.86(0.85-0.86)$ & $0.85(0.84-0.86)$ & $0.82(0.81-0.83)$ & $0.85(0.84-0.86)$ & $0.94(0.93-0.94)$ \\
\hline Coronary heart disease & 1298 & 557 & $0.90(0.89-0.92)$ & $0.90(0.88-0.91)$ & $0.87(0.84-0.89)$ & $0.90(0.88-0.91)$ & $0.96(0.96-0.97)$ \\
\hline Coronary heart disease+Diabetes & 274 & 118 & $0.93(0.93-0.94)$ & $0.94(0.92-0.96)$ & $0.91(0.88-0.95)$ & $0.94(0.92-0.95)$ & $0.98(0.97-1.00)$ \\
\hline Rhinallergosis & 152 & 66 & $0.71(0.64-0.79)$ & $0.69(0.61-0.79)$ & $0.80(0.73-0.86)$ & $0.70(0.64-0.76)$ & $0.79(0.73-0.84)$ \\
\hline Hypothyroidism & 1627 & 698 & $0.77(0.76-0.78)$ & $0.76(0.75-0.76)$ & $0.73(0.71-0.74)$ & $0.76(0.75-0.76)$ & $0.84(0.83-0.86)$ \\
\hline Hyperthyroidism & 751 & 322 & $0.72(0.71-0.72)$ & $0.73(0.71-0.74)$ & $0.73(0.71-0.75)$ & $0.73(0.71-0.74)$ & $0.79(0.77-0.81)$ \\
\hline Cervical spondylopathy & 311 & 134 & $0.71(0.66-0.75)$ & $0.71(0.69-0.73)$ & $0.73(0.64-0.81)$ & $0.71(0.69-0.73)$ & $0.78(0.78-0.80)$ \\
\hline Rheumatoid arthritis & 387 & 167 & $0.79(0.78-0.81)$ & $0.78(0.77-0.78)$ & $0.76(0.71-0.81)$ & $0.78(0.77-0.79)$ & $0.86(0.83-0.89)$ \\
\hline Chronic rhinitis & 313 & 135 & $0.61(0.58-0.64)$ & $0.60(0.58-0.62)$ & $0.57(0.56-0.57)$ & $0.61(0.58-0.63)$ & $0.66(0.60-0.72)$ \\
\hline Nephropathy & 564 & 242 & $0.73(0.72-0.74)$ & $0.77(0.75-0.80)$ & $0.81(0.79-0.84)$ & $0.76(0.75-0.78)$ & $0.84(0.82-0.85)$ \\
\hline Diabetes & 11545 & 4949 & $0.90(0.90-0.90)$ & $0.90(0.90-0.90)$ & $0.90(0.89-0.90)$ & $0.90(0.90-0.90)$ & $0.96(0.96-0.96)$ \\
\hline Gout & 2095 & 898 & $0.88(0.88-0.88)$ & $0.87(0.87-0.87)$ & $0.85(0.84-0.87)$ & $0.86(0.83-0.88)$ & $0.94(0.94-0.94)$ \\
\hline Parkinson's syndrome & 192 & 83 & $0.91(0.90-0.91)$ & $0.90(0.89-0.90)$ & $0.87(0.79-0.94)$ & $0.90(0.89-0.91)$ & $0.97(0.95-0.98)$ \\
\hline Stomach trouble & 1269 & 545 & $0.68(0.68-0.69)$ & $0.70(0.70-0.70)$ & $0.71(0.70-0.73)$ & $0.70(0.70-0.70)$ & $0.77(0.75-0.78)$ \\
\hline Chronic pharyngitis & 765 & 329 & $0.63(0.62-0.65)$ & $0.67(0.65-0.69)$ & $0.66(0.65-0.66)$ & $0.67(0.65-0.68)$ & $0.72(0.69-0.75)$ \\
\hline
\end{tabular}




\begin{tabular}{|c|c|c|c|c|c|c|c|}
\hline Lumbar disc protrusion & 377 & 162 & $0.77(0.72-0.81)$ & $0.77(0.73-0.80)$ & $0.70(0.63-0.77)$ & $0.75(0.70-0.79)$ & $0.85(0.82-0.88)$ \\
\hline Hepatitis B & 691 & 297 & $0.73(0.70-0.77)$ & $0.75(0.73-0.77)$ & $0.79(0.77-0.80)$ & $0.75(0.72-0.77)$ & $0.83(0.81-0.85)$ \\
\hline Hypertension+other diseases & 2360 & 1012 & $0.86(0.85-0.88)$ & $0.85(0.85-0.86)$ & $0.82(0.81-0.83)$ & $0.86(0.85-0.86)$ & $0.93(0.93-0.94)$ \\
\hline Coronary heart disease+other diseases & 98 & 43 & $0.88(0.84-0.92)$ & $0.87(0.84-0.89)$ & $0.83(0.76-0.90)$ & $0.86(0.83-0.88)$ & $0.94(0.91-0.97)$ \\
\hline Diabetes+other diseases & 365 & 157 & $0.90(0.87-0.94)$ & $0.90(0.87-0.94)$ & $0.89(0.84-0.94)$ & $0.90(0.86-0.94)$ & $0.96(0.93-0.98)$ \\
\hline Bronchial disease & 562 & 241 & $0.76(0.70-0.83)$ & $0.77(0.70-0.83)$ & $0.80(0.76-0.84)$ & $0.77(070-0.83)$ & $0.83(0.79-0.88)$ \\
\hline Other disease conditions & 2720 & 1167 & $0.68(0.67-0.70)$ & $0.69(0.67-0.71)$ & $0.69(0.66-0.73)$ & $0.69(0.67-0.71)$ & $0.75(0.74-0.77)$ \\
\hline Brain diseases & 251 & 108 & $0.86(0.81-0.90)$ & $0.86(0.82-0.91)$ & $0.83(0.75-0.90)$ & $0.87(0.82-0.91)$ & $0.93(0.91-0.95)$ \\
\hline Hepatic adipose infiltration & 803 & 115 & $0.82(0.78-0.87)$ & $0.81(0.76-0.86)$ & $0.75(0.67-0.82)$ & $0.82(0.77-0.87)$ & $0.92(0.89-0.94)$ \\
\hline Asthma & 1640 & 803 & $0.75(0.74-0.76)$ & $0.74(0.73-0.76)$ & $0.77(0.69-0.84)$ & $0.75(0.74-0.76)$ & $0.88(0.84-0.92)$ \\
\hline Other Cardiac diseases & 336 & 145 & $0.79(0.78-0.81)$ & $0.78(0.76-0.80)$ & $0.80(0.75-0.86)$ & $0.78(0.76-0.80)$ & $0.88(0.84-0.92)$ \\
\hline Heart disease & 224 & 96 & $0.89(0.87-0.90)$ & $0.89(0.85-0.92)$ & $0.91(0.87-0.94)$ & $0.89(0.86-0.92)$ & $0.94(0.90-0.99)$ \\
\hline Hepatopathy & 176 & 76 & $0.71(0.65-0.76)$ & $0.72(0.66-0.78)$ & $0.78(0.68-0.87)$ & $0.73(0.68-0.78)$ & $0.80(0.74-0.85)$ \\
\hline Pregnant & 54 & 24 & $0.83(0.76-0.90)$ & $0.82(0.76-0.88)$ & $0.85(0.79-0.92)$ & $0.82(0.77-0.86)$ & $0.91(0.90-0.93)$ \\
\hline Normal or non-normal condition & 91028 & 39012 & $0.83(0.83-0.83)$ & $0.82(0.82-0.82)$ & $0.81(0.81-0.81)$ & $0.84(0.84-0.84)$ & $0.9(0.90-0.90)$ \\
\hline
\end{tabular}


bioRxiv preprint doi: https://doi org/101101/855809; this version posted November 26, 2019. The copyright holder for this preprint (which was not certified by peer review) is the author/funder, who has granted bioRxiv a license to display the preprint in perpetuity. It is made available under aCC-BY-NC-ND 4.0 International license.

Extended data Figure 1. PEI networks in hypertension (a) and diabetes (b). In weighted graphs, green edges indicate positive weights, and red edges indicate negative weights. The color saturation and the width of the edges correspond to the absolute weight and scale relative to the strongest weight in the graph. At a minimum, the edge with absolute weight at this value is omitted. The circular layout is convenient to see how well the data conform to a model, but in order to show how the data clusters, another layout is more appropriate. A force-oriented layout was created by specifying layout = "spring". In principle, what this function does is that each node (connected and unconnected) repulses each other, and connected nodes also attract each other. The full view of these figures is provided in Supplementary Figures.

a
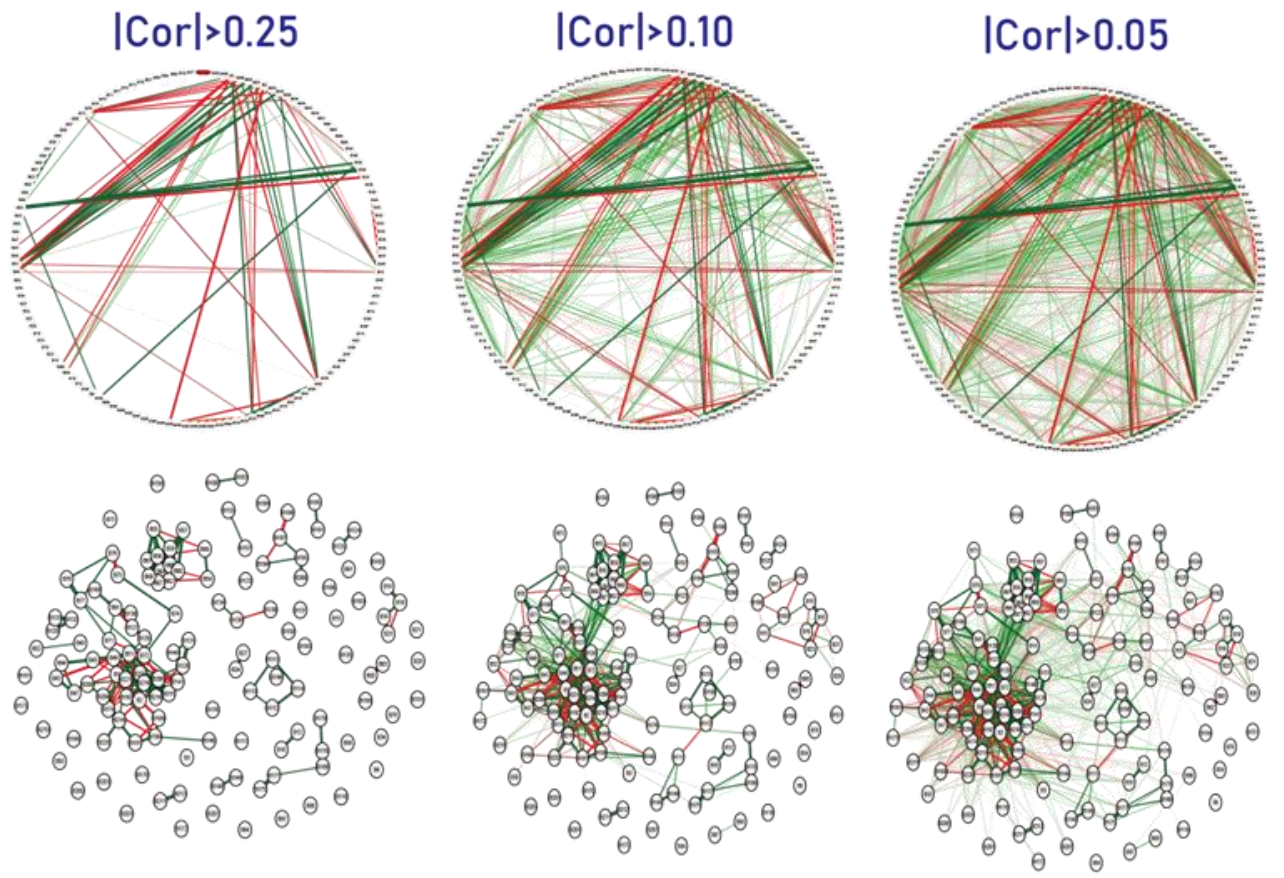

b

$\mid$ Corl $>0.25$
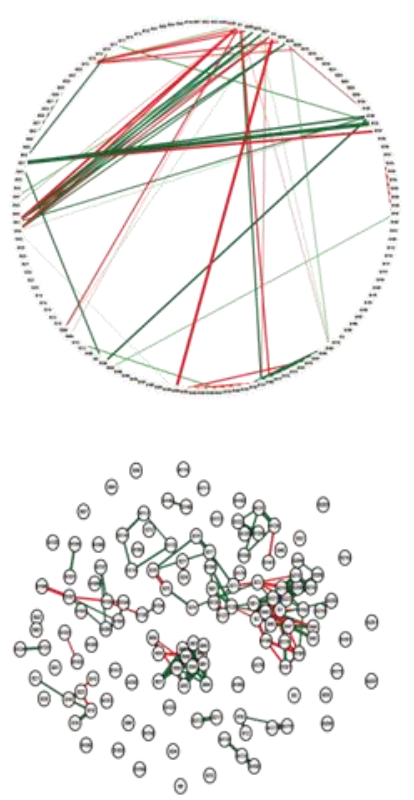

$\mid$ Cor $\mid>0.10$
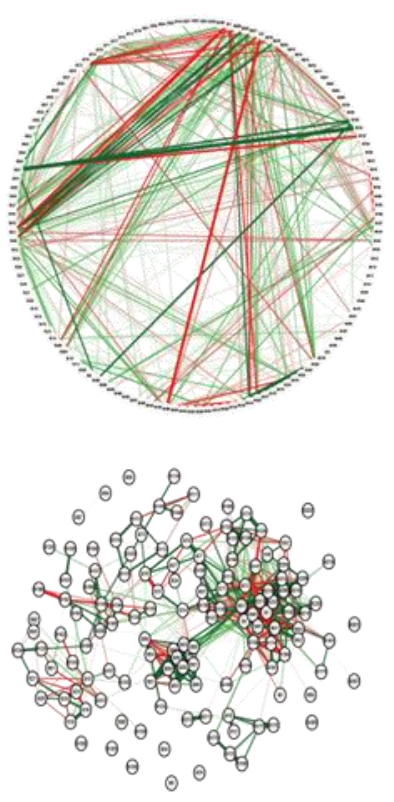

\section{|Cor|>0.05}
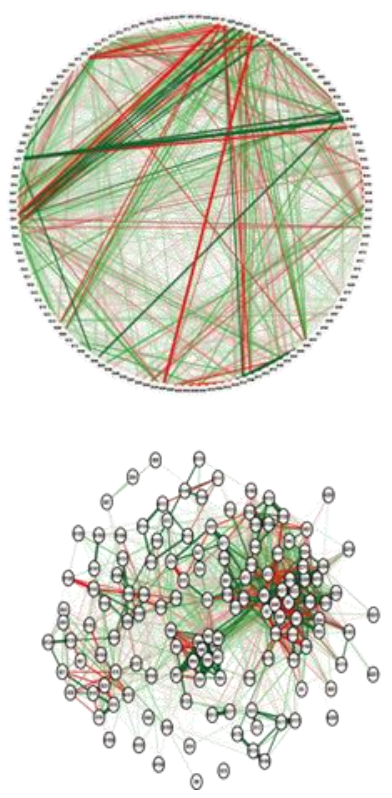
Extended data Figure 2. Odds ratios for HDL-C concentration in plasma from those with a normal physical status and those with diabetes. Both male and female subjects were included in this study.

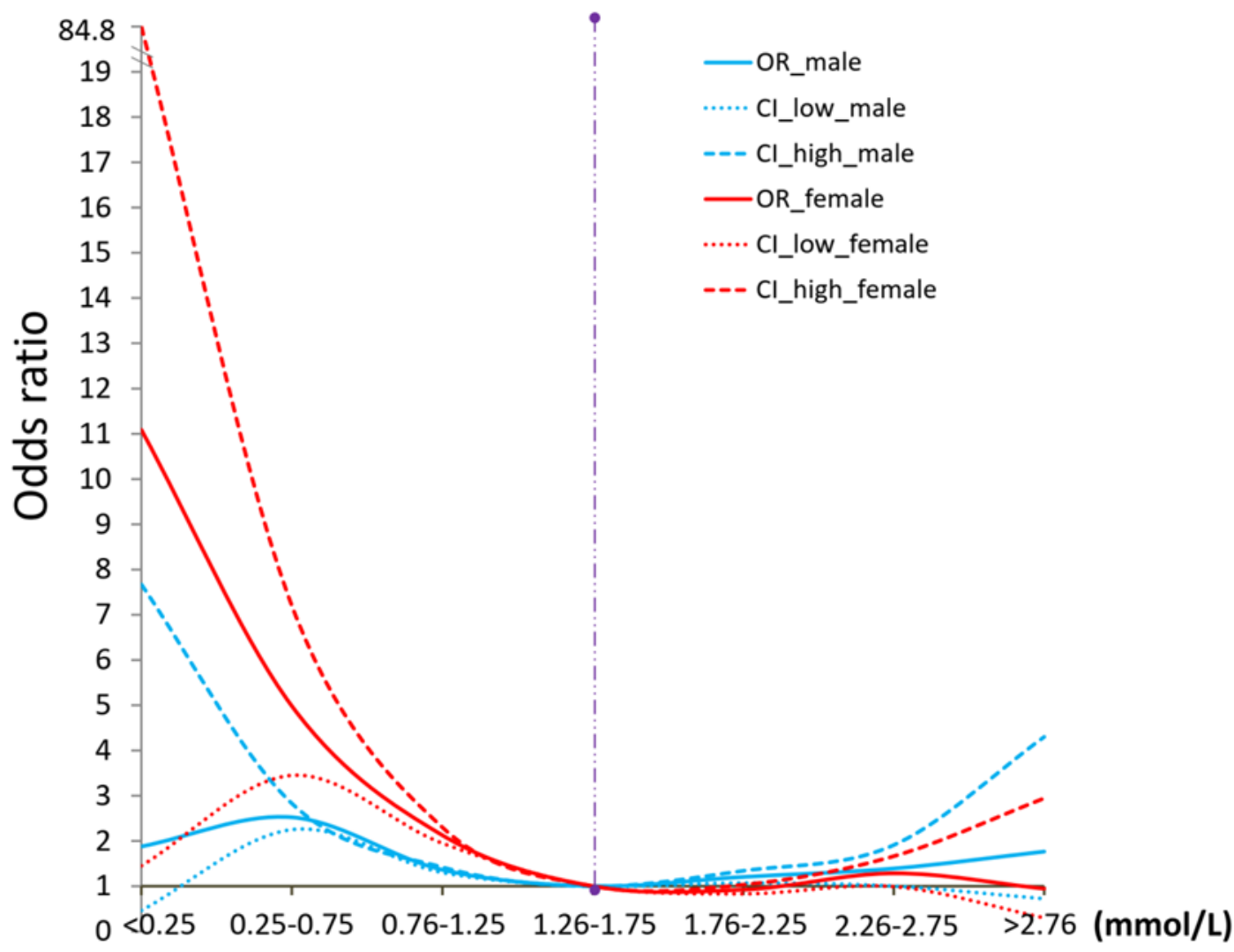




\section{Supplementary Tables}

Supplementary Table 1. PEI Correlations in Healthy status

Supplementary Table 2. PEI Correlations in Cholecystolithiasis

Supplementary Table 3. PEI Correlations in Hypertension

Supplementary Table 4. PEI Correlations in Hypertension+Diabetes

Supplementary Table 5. PEI Correlations in Hypertension+Coronary

Supplementary Table 6. PEI Correlations in Hypertensive+Diabetes+Coronary

Supplementary Table 7. PEI Correlations in Hyperlipidemia

Supplementary Table 8. PEI Correlations in Coronary heart disease

Supplementary Table 9. PEI Correlations in Coronary+Diabetes

Supplementary Table 10. PEI Correlations in Rhinallergosis

Supplementary Table 11. PEI Correlations in Hypothyroidism

Supplementary Table 12. PEI Correlations in Hyperthyroidism

Supplementary Table 13. PEI Correlations in Cervical spondylopathy

Supplementary Table 14. PEI Correlations in Rheumatoid arthritis

Supplementary Table 15. PEI Correlations in Chronic rhinitis

Supplementary Table 16. PEI Correlations in Nephropathy

Supplementary Table 17.PEI Correlations in Diabetes

Supplementary Table 18. PEI Correlations in Gout

Supplementary Table 19. PEI Correlations in Parkinson's syndrome

Supplementary Table 20. PEI Correlations in Stomach trouble

Supplementary Table 21. PEI Correlations in Chronic pharyngitis

Supplementary Table 22. PEI Correlations in Lumbar disc protrusion

Supplementary Table 23. PEI Correlations in Hepatitis B

Supplementary Table 24. PEI Correlations in Hypertension+other diseases

Supplementary Table 25. PEI Correlations in Coronary+others

Supplementary Table 26. PEI Correlations in Diabetes+others

Supplementary Table 27. PEI Correlations in Bronchial disease

Supplementary Table 28. PEI Correlations in Other disease conditions

Supplementary Table 29. PEI Correlations in Brain diseases 
Supplementary Table 30. PEI Correlations in Hepatic adipose infiltration

Supplementary Table 31. PEI Correlations in Asthma

Supplementary Table 32. PEI Correlations in Other Cardiac diseases

Supplementary Table 33. PEI Correlations in Heart disease

Supplementary Table 34. PEI Correlations in Hepatopathy

Supplementary Table 35. PEI Correlations in Pregnant

Supplementary Table 36. $\mathrm{P}$ values of PEIs in healthy physical status vs 34 unhealthy physical status adjusted for age and sex.

Supplementary Table 37. Optimal parameter combination of machine learning

\section{Supplementary codes}

